\title{
AM/CM Oxalate Precipitation and Washing Demonstration
}

by

S. B. Beck

in Westinghouse Savannah River Company

Savannah River Site

Aiken, South Carolina 29808

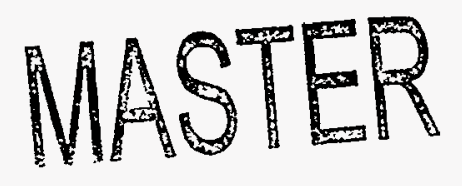

DOE Contract No. DE-AC09-89SR18035

This paper was prepared in connection with work done under the above contract number with the U.S.

Department of Energy. By acceptance of this paper, the publisher and/or recipient acknowledges the U.S.

Government's right to retain a nonexclusive, royalty-free license in and to any copyright covering this paper, along with the right to reproduce and to authorize others to reproduce all or part of the copyrighted paper. 


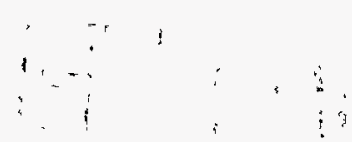

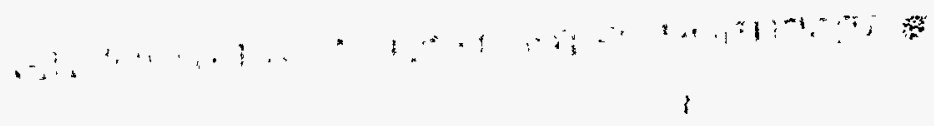


WSRC-TR-96-0116

June 11, 1996

\section{AM/CM OXALATE PRECIPITATION AND WASHING DEMONSTRATION}

\section{Distribution:}

NMPD

S. B. Speight, 704-14F

J. P. Duane, 704-F

W. B. Sumner, 703-F

T. R. Pfefferkorn, $221-14 \mathrm{~F}$

D. A. Ecklund, 703-F

T. F. Severynse, 704-F

W. H. Martin 676-15T

J. M. Anderson 704-15F
SRTC

T. Jones, 704-1T

D. Miller, 704-1T

G. Ramsey, 704-1T

D. Witt, 704-1T

L. M. Papouchado, 773-A

E. W. Holtzscheiter, 773-A

L. F. Landon, 704-T

T. S. Rudisill, 773-A

SRTC Records, 773-52A 


\section{DISCLAMMER}

This report was prepared as an account of work sponsored by an agency of. the United States Government. Neither the United States Government nor any agency thereof, nor any of their employees, makes any warranty, express or implied, or assumes any legal liability or. -responsibility for the accuracy, completeness, or usefulness of any information, apparatus, product, or process disclosed, or represents that its use would not infringe privately owned rights. Reference herein to any specific commercial product, process, or service by trade name, trademark, manufacturer, or otherwise does not necessarily constitute or imply its endorsement, recommendation, or favoring by the United States Government or any agency thereof. The views and opinions of authors expressed herein do not necessarily state or reflect those of the United States Government or any agency thereof.

This report has been reproduced directly from the best available copy.

Available to DOE and DOE contractors from the Office of Scientific and Technical Information, P.O. Box 62, Oak Ridge, TN 37831; prices available from (615) 57.6-8401.

Available to the public from the. National Technical-Information Service, U.S. Department of Commerce, 5285 Port Royal Road, Springfield, VA 22161: 


\section{DISCLAIMER}

Portions of this document may be illegible in electronic image products. Images are produced from the best available original document. 



\title{
$\mathrm{Am} / \mathrm{Cm}$ Oxalate Precipitation and Washing Demonstration WSRC-TR-96-0116
}

\author{
Scot B. Beck \\ Westinghouse Savannah River Site
}

June 11, 1996 


\section{Contents}

1 Introduction 1

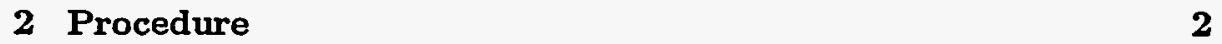

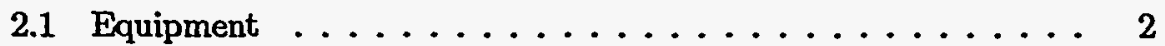

2.2 Solution Preparation ................. 3

2.2.1 Tank 17.1 Simulant Preparation . . . . . . . . . 3

2.2.2 Oxalic Acid Preparation ... . . . . . . . . . 3

2.2.3 Oxalic Acid/Nitric Acid Wash Solution Preparation ... 3

2.3 Oxalate Precipitation $\ldots \ldots \ldots \ldots \ldots \ldots \ldots$

2.4 Oxalate Washing . . . . . . . . . . . . 5

2.5 Shut Down ................... 5

3 Results 9

3.1 Precipitate Volume ................... 9

3.2 Settling Rate of Precipitate . . . . . . . . . . . . 9

3.3 Solubility of Metals and Lanthanides . . . . . . . . . . . 10

3.4 Effect of Washing Volume . . . . . . . . . . . . 12

4 Discussion 27

4.1 Maximizing Lanthanide Retention . . . . . . . . . . 27

5 Appendix 30

.1 Constants for Derivations . . . . . . . . . . . 30

.2 Sampling Protocol . . . . . . . . . . . . 30 


\section{List of Tables}

2.1 Operating conditions for the $\mathrm{Am} / \mathrm{Cm}$ oxalate precipitation and washing demonstration. .............. 6

2.2 Iron, aluminum, and sodium sources for Tank 17.1 simulant solution. ...................... 6

2.3 Trace metal and lanthanide sources for Tank 17.1 simulant solution. 6

2.4 Target and demonstration anion concentration for Tank 17.1 simulant solution. Nitric acid concentrations are high due to the concentration of the solution by $1.25 . \ldots \ldots \ldots \ldots$

2.5 Target and demonstration cation concentrations for Tank 17.1 simulant solution. Cation concentrations are elevated due to the 1.25 concentration of the solution. . . . . . . . . . . .

2.6 Target and demonstration lanthanide concentrations for Tank 17.1 simulant solution. Concentrations are elevated by approximately 1.25 due to concentrating the solution. The analytical results show the additional Europium and Gadolinium substituted for Americium and Curium. . . . . . . . . . . .

3.1 Volume of heavy particles as a function of time for 4 tests. . . . 17

3.2 Volume of intermediate particles as a function of time for 4 tests. 17

3.3 Volume of smallest particles as a function of time for 2 tests. The distinction between the clear supernate and fines was evident until approximately four hours into the test. At that point, the supernate remained slightly coudly. . . . . . . . . .

3.4 The solubility of the lanthanides is recorded during each phase of the demonstration. Predicted lanthanide concentrations are based on the nitric acid-solubility of the lanthanides and a 5 gallon wash. ................... 18

3.5 The solubility of the metal oxalates is measured at each stage in the demonstration. ................ 19

.1 The above table shows how many samples were taken during the digestion and settling periods, the time the samples were taken, and the location of the sample with respect to the bottom of the vessel. . . . . . . . . . . . . . . . . 
.2 This table shows the location and timing of samples to establish the supernate concentration profile. The effect of washing is also measured with samples taken during the washing procedure and the supernate after 24 hours of settling. . . . . . . . . . .

.3 The above table shows how the digestion and settling samples samples were submitted for analysis. The letter "a" indicates full analysis, and the letter "s" indicates solids analysis. . . . . . .

.4 This table shows the analysis required for the concentration profile and the washing procedure. The letter "a" indicates full analysis, and the letter " $\mathrm{s}$ " indicates solids analysis. . . . . . . . 32

.5 Observations at the start of digestion. . . . . . . . . . 33

.6 Sampling protocol during the settling stage. . . . . . . . . 33 


\section{List of Figures}

2.1 Equipment necessary to perform the $\mathrm{Am} / \mathrm{Cm}$ Oxalate Precipitation and Washing Demonstration. . . . . . . . . .

3.1 Total solids, insoluble solids, and soluble solids during the settling stage of the demonstration. The insoluble solids settled in the first 30 minutes of the eight hour period. . . . . . . . . . .

3.2 The height of the solid liquid interface (in a $2 \mathrm{~L}$ graduated cyliner) is plotted versus time for each of the three particle size distributions in the oxalate precipitate. The large and intermediate sized particles fall out of solution within $\mathbf{2 0}$ minutes, and the smallest particles remain in solution for approximately 14 hours. Each line is surrounded by the $95 \%$ confidence on the regression analysis. 21

3.3 Metal removal efficiency and lanthanide retention as a function of wash volume. . . . . . . . . . . . . . 22

3.4 Lanthanide concentrations as a function of wash cycle. Cylce 0 is the supernate concentration of the first decant. . . . . . 23

3.5 Metal concentrations as a function of wash cycle. Cycle 0 represents the initial decant supernate. . . . . . . . . . . . 24

3.6 Nitric acid concentration following each wash cycle compared with the washing model. This figure shows the inablity of analytical to accurately determine the anion concentrations. The solubility dependence on nitric acid concentration will use the washing model nitric acid concentration. . . . . . . . . 25

3.7 Lanthanide solubilities as a function of nitric acid concentration. The oxalic acid concentration remained $0.3 \mathrm{M}$ after the digestion

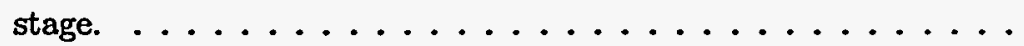

4.1 Rate of loss of Eu with wash volume as a function of intitial nitric acid concentration and wash nitric acid concentration. . . . . . 


\begin{abstract}
Sixteen gallons of concentrated Tank 17.1 simulant solution (europium, gadolinium, and cerium substituted for americium, curium, and plutonium) have been reacted with 10 gallons of oxalic acid ( $0.3 \mathrm{M}$ excess) for the purpose of determining (1) the solubility of the various lanthanide and metal oxalates, (2) the amount of oxalate precipitate formed per mole of lanthanides, (3) the settling rate of the oxalate precipitate, and (4) the required clearance for the suction tube in order to decant the supernate. The oxalate precipitate was washed 5 times with a 6 gallon $0.5 \mathrm{M} \mathrm{HNO} 3 / 0.25 \mathrm{M} \mathrm{H}_{2} \mathrm{C}_{2} \mathrm{O}_{4}$ solution.

The solubility differences between the metal oxalates and lanthaninde oxalates yields on average $96 \%$ removal of the metals and $3.5 \%$ loss of the lanthanides after five washing cycles. The $3.5 \%$ lanthanide loss is largely a function of the lanthanum oxalate solubility ( $15 \%$ loss). All other lanthanide oxalate losses were $\ll 1 \%$. Approximately 0.5 liters of oxalate precipitate were formed per mole of lanthanides. The oxalate precipitate settled very quickly onto all horizontal surfaces in the reaction tank. The bulk of the precipitate settled within 30 minutes with the fines requiring 8-14 hours for the supernate to become completely clear. Finally, the decant tube was lowered to within $\frac{1}{2}$ inch of the precipitate before entrainment was observed with linear velocities ranging $60 \frac{\mathrm{ft}}{\min }-220 \frac{\mathrm{ft}}{\min }$ in the sample tube.
\end{abstract}




\section{Chapter 1}

\section{Introduction}

The purpose of this report is to discuss the findings of the $\mathrm{Am} / \mathrm{Cm}$ Oxalate Precipitation and Washing Demonstration carried out at TNX during December 1995. This demonstration consisted of two steps: oxalate precipitation and precipitate washing. The first step reacted $\mathrm{Am} / \mathrm{Cm}$ simulant solution with oxalic acid resulting in the formation of insoluble lanthanide oxalates and soluble metal oxalates. The second step consisted of washing the precipitate with equal volumes of a nitric acid/oxalic acid solution to remove unwanted cations (miscellaneous metals) from the slurry. Quantitative results consist of: the solubility of the metallic impurities and lanthanide oxalates under process conditions, the settling rate of the oxalates, the specific volume of the oxalate precipitate, and the minimum distance the solution transfer jet can be placed from the oxalate solids to prevent entrainment. Finally, discussion of how to decrease lanthanide losses is presented in terms of transfer jet location, initial nitric acid concentration, and wash nitric acid concentration. Solubilizing the precipitate and adjusting the nitric acid concentration prior to vitrification were not performed in this demonstration. 


\section{Chapter 2}

\section{Procedure}

The procedures for this demonstration covered the areas of solution preparation, oxalate precipitation, oxalate washing, and equipment shut down. Solution preparation consisted of making solutions for the simulant, the oxalic acid, and the nitric acid/oxalic acid wash. Oxalate precipitation consisted of heating the simulant solution and oxalic acid, adding the oxalic acid to the simulant solution, and allowing the lanthanide oxalates to settle. Oxalate washing consisted of decanting the original supernate, washing the remaining slurry with an equal volume wash solution, and allowing the solids to settle overnight. The key parameters and operating conditions are summarized in Table 2.1. Additional details concerning sampling protocol and operational procedures are given in Chapter 5.

\subsection{Equipment}

Figure 2.1 shows the equipment necessary to perform the $\mathrm{Am} / \mathrm{Cm}$ Oxalate Precipitation and Washing Demonstration. The simulant solution is heated, the heated oxalic acid is transferred to the tank, the reaction proceeds, and the contents are allowed to settle for further washing stages. Samples are taken at various heights in the tank during each stage of the demonstration (digestion, settling, and washing).

The equipment for this demonstration consisted of:

1. one 50 gallon stirred tank with baffles and heating coils,

2. one variable height sample tube,

3. two heating baths

4. carboys for the simulant solution,

5. carboys for the axalic acid solution,

6. carboys for the wash solution, 
7. carboys for the wash supernates,

8. pump for taking samples,

9. pump for oxalic acid addition,

10. and thermocouples.

\subsection{Solution Preparation}

\subsubsection{Tank 17.1 Simulant Preparation}

Simulant preparation consists of mixing available chemicals in the correct proportions such that the differences between analytical results for the simulant and Tank 17.1 are minimized. Available chemicals consist primarily of metal and lanthanide nitrates and are presented in Tables 2.2 and 2.3. Tables 2.4, 2.5, and 2.6 list Tank 17.1 analytical results for the anion, cation, and lanthanide concentrations along with the concentrations used for this demonstration. Additional amounts of europium, gadolinium, and cerium have been added, on an equal molar basis, to substitute for americium, curium, and plutonium respectively. During simulant preparation, four gallons of $\mathrm{H}_{2} \mathrm{O}$ were mistakenly not added to the solution. This mistake resulted in the simulated solution being more concentrated than that in Tank 17.1 by a factor of $\frac{20}{16}=1.25$.

\subsubsection{Oxalic Acid Preparation}

The target excess oxalic acid concentration was $0.3 \mathrm{M}$. This condition was achieved by maintaining the nitric acid concentration $<1 \mathrm{M}$ and adding one volume of $0.9 \mathrm{M}$ oxalic acid to two volumes of feed. The oxalic acid was dissolved into 5 gallons of $\mathrm{H}_{2} \mathrm{O}$. This concentrated solution was added to a 6 gallon carboy and heated to a temperature of $52^{\circ} \mathrm{C}$. The remaining 5 gallons of $\mathrm{H}_{2} \mathrm{O}$ were added to the simulant and heated with the simulant to $62^{\circ} \mathrm{C}$. The concentrated oxalic acid was added to the simulant mixture in approximately 2 minutes. Previous addition rates have varied from 15-20 minutes. The rapid addition of oxalic acid may have resulted in the generation of some fines due to rapid nucleation. The resulting mixture measured 26 gallons.

\subsubsection{Oxalic Acid/Nitric Acid Wash Solution Preparation}

The oxalic acid/nitric acid wash solution consisted of mixing nitric and oxalic acid in the correct quantities to obtain a $0.5 \mathrm{M}$ nitric acid and $0.25 \mathrm{M}$ oxalic acid solution. Approximately 5 gallons of this mixture were prepared for each washing cycle. Five gallons represent the amount of material left in the tank after pumping out with the sample tube. Due to the conical bottom of the tank, this remaining 5 gallons is unaccessible to the sample tube and is therefore the slurry volume for washing. 


\subsection{Oxalate Precipitation}

The oxalate precipitation was performed using the following procedure and operating limits .

1. Add $\mathrm{H}_{2} \mathrm{O}$ to the vessel.

2. Turn on stirrer.

3. Begin preheating the $\mathrm{H}_{2} \mathrm{O}$ in the vessel to $60^{\circ} \mathrm{C}$.

4. Charge the vessel with the lanthanide and metal salts.

5. Begin air purge to the vessel.

6. Vessel temperature usually lags the bath temperature by $5^{\circ} \mathrm{C}$, set the bath to $65^{\circ} \mathrm{C}$.

7. Add $\mathrm{H}_{2} \mathrm{O}$ to oxalic acid container.

8. Add oxalic acid to the oxalic acid container.

9. Begin preheating the oxalic acid solution to $60^{\circ} \mathrm{C}$. Solubility of oxalic acid in $\mathrm{H}_{2} \mathrm{O}$ does not appear to be a problem.

10. Pull sample of both the simulant solution and oxalic solution for analysis.

11. Transfer oxalic acid solution into simulant vessel.

12. Cool the resulting solution to $40^{\circ} \mathrm{C}$.

13. Cooling can be accelerated by opening the hinged lid to evacuate the vapor space.

14. Once the temperature reaches $40^{\circ} \mathrm{C}$, start the timer for the 4 hour digestion period.

15. Decrease the temperature in the vessel to $35^{\circ} \mathrm{C}$.

16. Continue to stir the solution during the digestion period.

17. Pull sample to determine the excess oxalic acid concentration.

18. After 4 hours, turn off the stirrer.

19. Start the timer for the settling period.

20. The settling period is 8 hours.

21. Determine the solution height with the sample tube.

22. Divide the solution height into 5 intervals.

23. Pull samples at these 5 intervals at one hour intervals during the settling period.

24. At the end of 8 hours, decant the supernate until the solid interface is discovered. 


\subsection{Oxalate Washing}

The solid-liquid interface was located approximately 0.25 inches off the bottom of the tank. Due to the sample tube location, the oxalate was washed with 5 gallons of the $0.25 \mathrm{M}$ oxalic acid/ $0.5 \mathrm{M}$ nitric acid solution. The first wash was agitated for 1 hour and the solids were allowed to settle overnight. The remaining washes also used 5 gallons of wash solution, but they were agitated only 15 minutes. Samples were taken from each wash solution and supernate.

1. Add a volume of nitric acid/oxalic acid solution equal to the solids volume.

2. Turn on agitator.

3. Agitate for $15-30$ minutes.

4. During agitation, pull sample.

5. Turn off heating bath.

6. Allow solids to settle overnight.

7. Decant supernate, store in carboy.

8. Pull sample of supernate.

9. Repeat washing steps 4 more times.

\subsection{Shut Down}

After washing was completed, the solids were removed for two reasons. First, an accurate measurement of the settling rate needed to be determined. Second, dissolution of the oxalate in nitric acid produces nitrogen oxides which can not be handled in the existing apparatus. The solids drop out of solution relatively quickly, but the fines are slower to fall out. All of the washing stages used a $24 \mathrm{hr}$ settling period. At the end of this period, all of the solids were on the bottom and the supernate was crystal clear. Observing the last washing stage, showed that the fines had not settled after an 8 hour period. The solids were removed to recreate settling and to measure the total amount of oxalate produced.

1. Ro-suspend solids in distilled water.

2. Pump slurry out of vessel and transfer into carboy.

3. Allow solids to settle.

4. Decant $\mathrm{H}_{2} \mathrm{O}$.

5. Perform settling measurements in $2 \mathrm{~L}$ graduated cylinder.

6. Redissolve oxalates for melter. 


\begin{tabular}{|l|c|}
\hline Key Parameters & Value \\
\hline \hline Simulant Volume & 16 gallons \\
\hline Source Oxalic Acid Concentration & $1.6 \mathrm{M}$ \\
\hline Nitric Acid Concentration & $1.0 \mathrm{M}$ \\
\hline Oxalic Acid Temperature & $60^{\circ} \mathrm{C}$ \\
\hline Excess Oxalic Acid Concentration & $0.288 \mathrm{M}$ \\
\hline Digestion Time & $4 \mathrm{hrs}$ \\
\hline Digestion Temperature & $40^{\circ} \mathrm{C}$ \\
\hline Settling Time & 8 hours \\
\hline Settling Temperature & $35^{\circ} \mathrm{C}$ \\
\hline Wash Solution Composition & $0.25 \mathrm{M}$ Oxalic Acid/0.5M HNO 3 \\
\hline Wash Temperature & $\leq 35^{\circ} \mathrm{C}$ \\
\hline Wash Volume & Equal to Slurry Volume (6 gallons) \\
\hline Number of Wash Cycles & 5 \\
\hline
\end{tabular}

Table 2.1: Operating conditions for the $\mathrm{Am} / \mathrm{Cm}$ oxalate precipitation and washing demonstration.

\begin{tabular}{|c|c|c|}
\hline Source of Iron & Source of Aluminum & Source of Sodium \\
\hline $\mathrm{Fe}\left(\mathrm{SO}_{4}\right) \cdot 7 \mathrm{H} 2 \mathrm{O}$ & $\mathrm{Al}_{2}\left(\mathrm{SO}_{4}\right)_{3} \cdot 18 \mathrm{H}_{2} \mathrm{O}$ & $\mathrm{NaNO}_{3}$ \\
\hline $\mathrm{FePO}_{4} \cdot 2 \mathrm{H} 2 \mathrm{O}$ & $\mathrm{AlF}_{3} \cdot 3.5 \mathrm{H}_{2} \mathrm{O}$ & $\mathrm{NaNO}_{2}$ \\
\hline $\mathrm{FeCl}_{3} \cdot 6 \mathrm{H}_{2} \mathrm{O}$ & $\mathrm{Al}\left(\mathrm{NO}_{3}\right)_{3} \cdot 9 \mathrm{H}_{2} \mathrm{O}$ & $\mathrm{Na}_{2} \mathrm{~B}_{4} \mathrm{O}_{7} \cdot 10 \mathrm{H}_{2} \mathrm{O}$ \\
\hline $\mathrm{Fe}_{2}\left(\mathrm{C}_{2} \mathrm{O}_{4}\right)_{3} \cdot 5 \mathrm{H} 2 \mathrm{O}$ & & $\mathrm{Na}_{2} \mathrm{SiO}_{3} \cdot 9 \mathrm{H}_{2} \mathrm{O}$ \\
\hline $\mathrm{Fe}\left(\mathrm{NO}_{3}\right)_{3} \cdot 9 \mathrm{H} 2 \mathrm{O}$ & & $\mathrm{Na}_{2} \mathrm{C}_{2} \mathrm{O}_{4}$ \\
\hline
\end{tabular}

Table 2.2: Iron, aluminum, and sodium sources for Tank 17.1 simulant solution.

\begin{tabular}{|l|l|}
\hline Source of Trace Metals & Source of Lanthanides \\
\hline \hline $\mathrm{Cr}\left(\mathrm{NO}_{3}\right)_{3} \cdot 9 \mathrm{H}_{2} \mathrm{O}$ & $\mathrm{La}\left(\mathrm{NO}_{3}\right)_{3} \cdot 6 \mathrm{H}_{2} \mathrm{O}$ \\
\hline $\mathrm{Mn}\left(\mathrm{NO}_{3}\right)_{2} \cdot 4 \mathrm{H}_{2} \mathrm{O}$ & $\mathrm{Ce}\left(\mathrm{NO}_{3}\right)_{3} \cdot 6 \mathrm{H}_{2} \mathrm{O}$ \\
\hline $\mathrm{Ni}\left(\mathrm{NO}_{3}\right)_{2} \cdot 6 \mathrm{H}_{2} \mathrm{O}$ & $\mathrm{Pr}\left(\mathrm{NO}_{3}\right)_{3} \cdot 6 \mathrm{H}_{2} \mathrm{O}$ \\
\hline $\mathrm{KNO}_{3}$ & $\mathrm{Nd}\left(\mathrm{NO}_{3}\right)_{3} \cdot 6 \mathrm{H}_{2} \mathrm{O}$ \\
\hline $\mathrm{K}_{2} \mathrm{C}_{2} \mathrm{O}_{4} \cdot \mathrm{H}_{2} \mathrm{O}$ & $\mathrm{Sm}\left(\mathrm{NO}_{3}\right)_{3} \cdot 6 \mathrm{H}_{2} \mathrm{O}$ \\
\hline $\mathrm{Zr}\left(\mathrm{NO}_{3}\right)_{4} \cdot 5 \mathrm{H}_{2} \mathrm{O}$ & $\mathrm{Eu}\left(\mathrm{NO}_{3}\right)_{3} \cdot 5 \mathrm{H}_{2} \mathrm{O}$ \\
\hline $\mathrm{Ca}\left(\mathrm{NO}_{3}\right)_{2} \cdot 4 \mathrm{H}_{2} \mathrm{O}$ & $\mathrm{Gd}\left(\mathrm{NO}_{3}\right)_{3} \cdot 6 \mathrm{H}_{2} \mathrm{O}$ \\
\hline $\mathrm{Zn}\left(\mathrm{NO}_{3}\right)_{2} \cdot 6 \mathrm{H}_{2} \mathrm{O}$ & \\
\hline
\end{tabular}

Table 2.3: Trace metal and lanthanide sources for Tank 17.1 simulant solution. 


\begin{tabular}{|l|c|c|}
\hline Anions & Tank 17.1 (g/L) & Demonstration (g/L) \\
\hline \hline $\mathrm{NO}_{2}^{-1}$ & 0.828 & 0.1 \\
\hline $\mathrm{NO}_{3}^{-1}$ & 62.0 (denitration) & 99.1 \\
\hline $\mathrm{SO}_{4}^{-2}$ & 9.6 & 11.6 \\
\hline $\mathrm{C}_{2} \mathrm{O}_{4}^{-2}$ & 1.232 & 0.212 \\
\hline $\mathrm{F}^{-1}$ & 0.21 & 0.1 \\
\hline $\mathrm{Cl}^{-1}$ & 0.98 & 1.06 \\
\hline $\mathrm{PO}_{4}^{-3}$ & 1.24 & 0.082 \\
\hline
\end{tabular}

Table 2.4: Target and demonstration anion concentration for Tank 17.1 simulant solution. Nitric acid concentrations are high due to the concentration of the solution by 1.25 .

\begin{tabular}{|l|c|c|}
\hline Cations & Tank 17.1 $(\mathrm{g} / \mathrm{L})$ & Demonstration $(\mathrm{g} / \mathrm{L})$ \\
\hline \hline $\mathrm{Fe}^{+3}$ & 4.96 & 6.48 \\
\hline $\mathrm{Al}^{+3}$ & 1.07 & 1.49 \\
\hline $\mathrm{Na}^{+1}$ & .67 & 0.55 \\
\hline $\mathrm{Cr}^{+3}$ & .286 & 0.39 \\
\hline $\mathrm{Mn}^{+2}$ & .237 & 0.32 \\
\hline $\mathrm{Ni}^{+2}$ & .229 & 0 \\
\hline $\mathrm{K}^{+1}$ & .215 & 0.00275 \\
\hline $\mathrm{Zr}^{+4}$ & $4.00 \times 10^{-3}$ & 0 \\
\hline $\mathrm{B}^{+3}$ & $1.04 \times 10^{-2}$ & 0 \\
\hline $\mathrm{Ca}^{+2}$ & .066 & 0.1 \\
\hline $\mathrm{Si}^{+4}$ & $1.79 \times 10^{-2}$ & $2.74 \times 10^{-3}$ \\
\hline $\mathrm{Zn}^{+2}$ & $2.09 \times 10^{-2}$ & $4 \times 10^{-2}$ \\
\hline
\end{tabular}

Table 2.5: Target and demonstration cation concentrations for Tank 17.1 simulant solution. Cation concentrations are elevated due to the 1.25 concentration of the solution.

\begin{tabular}{|l|c|c|}
\hline Lanthanides & Tank 17.1 (g/L) & Demonstration (g/L) \\
\hline \hline $\mathrm{La}^{+3}$ & 0.7 & 0.93 \\
\hline $\mathrm{Pr}^{+3}$ & 0.8 & 1.01 \\
\hline $\mathrm{Nd}^{+3}$ & 1.7 & 1.42 \\
\hline $\mathrm{Sm}^{+3}$ & 0.4 & 0.55 \\
\hline $\mathrm{Eu}^{+3}$ & 0.08 & 0.58 \\
\hline $\mathrm{Gd}^{+3}$ & 0.2 & 0.41 \\
\hline
\end{tabular}

Table 2.6: Target and demonstration lanthanide concentrations for Tank 17.1 simulant solution. Concentrations are elevated by approximately 1.25 due to concentrating the solution. The analytical results show the additional Europium and Gadolinium substituted for Americium and Curium. 
Am/Cm Oxalate Precipitation and Washing Demonstration

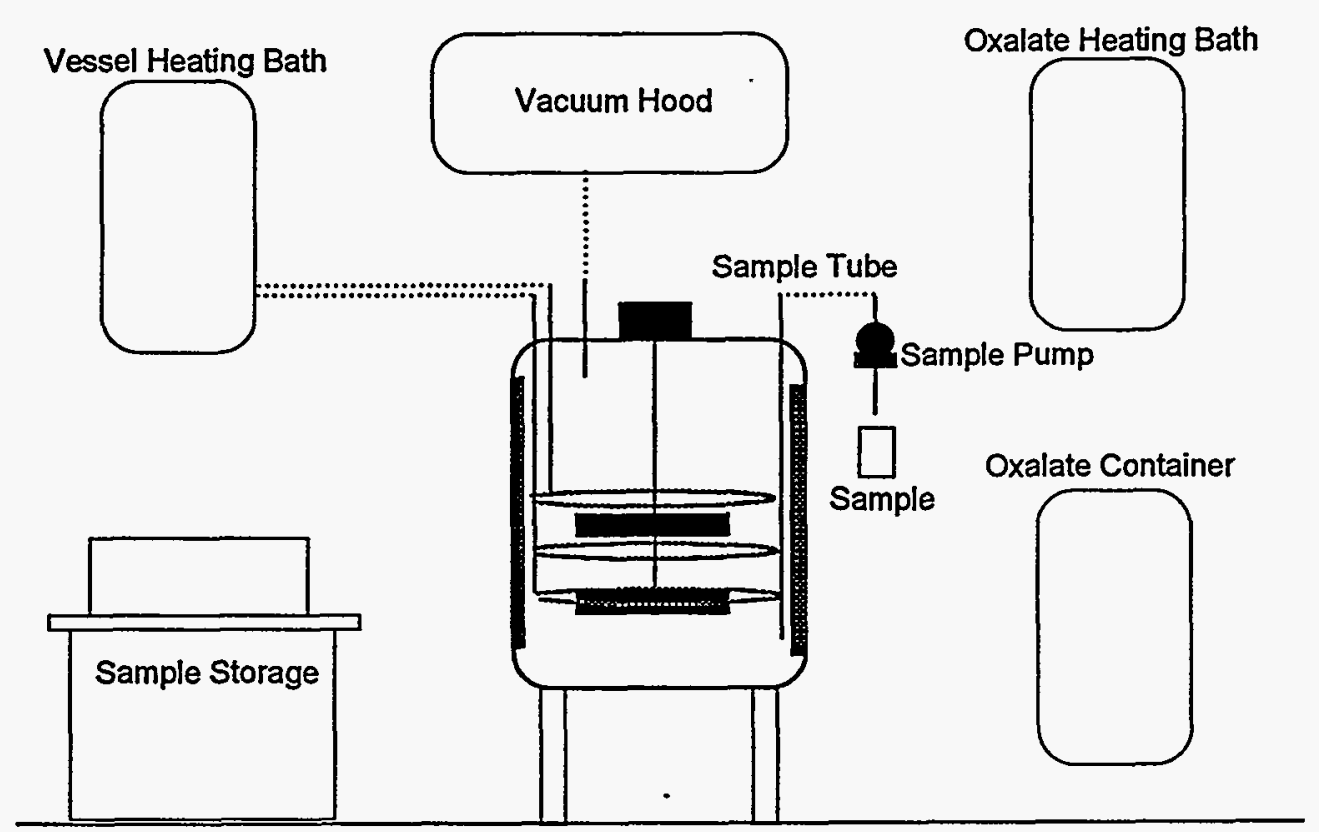

Figure 2.1: Equipment necessary to perform the Am/Cm Oxalate Precipitation and Washing Demonstration. 


\section{Chapter 3}

\section{Results}

The Am/Cm oxalate precipitation and washing demonstration revealed the volume of precipitate, the settling rate of this precipitate, the metal and lanthanide solubilities as a function of nitric acid concentration, and the effect wash volume has on lanthanide retention and washing efficiency. The volume of precipitate is the only result not determined in situ. The settling rate of the lanthanides was determined by measuring the insoluble solids concentration as a function of time and height in the tank. The metal and lanthanide solubilities were determined by the concentrations of these quantities in the supernate following the settling stage and subsequent washing stages. Finally, the effect of different wash volumes on the washing efficiency is determined by using both constant and variable solubility washing equations.

\subsection{Precipitate Volume}

The conical shape of the tank and the small precipitate volume prevented in situ volume measurement. The sample tube was only designed to reach to the top of the conical section, Figure 2.1. In order to determine the volume of solids, the solid precipitate was carefully transferred from the tank to a graduated cylinder. One liter of precipitate was formed from the 2 moles of lanthanide nitrates in the simulant solution. This ratio corresponds to $0.5 \mathrm{~L} / \mathrm{mole}$ of lanthanide and compares favorably with previous work.

\subsection{Settling Rate of Precipitate}

The settling rate of the oxalate precipitate was determined two different ways. First, $125 \mathrm{ml}$ samples were pulled during the settling period and tested for insoluble solids. Figure 3.1 shows the weight percent insoluble solids during the eight hour settling stage. This method revealed a very rapid settling of the lanthanide oxalates in the first 30 minutes. The second method reproduced the settling stage in a $2 \mathrm{~L}$ glass graduated cylinder by using the lanthanide oxalate 
removed from the tank at the end of the experiment and an equal volume of $0.5 \mathrm{M}$ nitric acid / $0.25 \mathrm{M}$ oxalic solution. Three distinct layers resulted in these tests suggesting three sizes of particles. Tables 3.1, 3.2, and 3.3 show the results of the settling tests. Figure 3.2 shows the settling rates of three distinct layers: primary settling rates of 15-20 minutes for the large material and 14 hours for the fines. Both in-tank at out-of-tank settling tests revealed that the primary settling occurs in a 30 minute period.

\subsection{Solubility of Metals and Lanthanides}

Separation the lanthanide oxalates from the metal oxalates results from solubility differences. From previous work and the work performed in this demonstration, the solubility of the metal oxalates is not dependent upon the nitric acid concentration. The nitric acid concentration changes after every wash cycle beginning with $1 \mathrm{M}$ and decreasing towards the wash concentration of $0.5 \mathrm{M}$. Table 3.5 shows the concentration of the metal oxalates in the simulant solution, the initial supernate, and the supernate following each washing cycle. Figure 3.5 shows that the concentration of the metal oxalates is a linear function of wash cycle when plotted on a semilog plot. This fact means that the solubility of the metal oxalates remains constant throughout the wash process. Therefore, the concentration of these oxalates is predicted by the following washing model, Equation 3.1, where $C_{S p e c i e s,} C_{y c l e}$ is the concentration of the species after so many wash cycles, $S_{S p e c i e s}$ is the solubility of the species, $V_{s}$ is the volume of the initial slurry after the first decant, and $V_{w}$ is the volume of wash solution.

$$
C_{\text {Species, }, \text { ycle }}=S_{\text {Species }}\left(\frac{V_{s}}{V_{s}+V_{w}}\right)^{C y c l e}
$$

For a wash volume equal to the slurry volume, $\frac{V_{s}}{V_{s}+V_{w}}=0.5$. For the following analysis, $\frac{V_{s}}{V_{a}+V_{w}}$ is set equal to $a$. Equations $3.2,3.3,3.4,3.5$, and 3.6 represent the concentrations of iron, manganese, aluminum, sodium, and chromium in $\mathrm{g} / \mathrm{L}$ as a function of wash cycle (i).

$$
\begin{aligned}
C_{F e, i} & =4 a^{i}=[g / L] \\
C_{M n, i} & =0.2 a^{i}=[g / L] \\
C_{A l, i} & =1 a^{i}=[g / L] \\
C_{n a, i} & =0.3 a^{i}=[g / L] \\
C_{C r, i} & =0.2 a^{i}=[g / L]
\end{aligned}
$$


Table 3.5 compares the concentrations of the metal oxalates with that predicted by the above washing model. Prediction of the metal oxalate concentrations is a function of the solubility established in the supernate after settling and a material balance on the tank.

The concentration of the lanthanides after each wash cycle is more difficult to calculate, because the solubility of the lanthanides is a function of the nitric acid concentration which is changing during each wash cycle. Therefore, to predict the separation of the lanthanides from the metal oxalates one must determine the solubility of each of the lanthanides in different nitric acid concentrations. The wash supernate from each washing cycle provides this information. Table 3.4 shows the concentration of the lanthanide oxalates in the simulant solution, the initial supernate, and the supernate following each washing cycle. Figure 3.4 shows that the concentration of the metal oxalates is not a linear function of wash cycle when plotted on a semilog plot. This fact means that the solubility of the lanthanide oxalates is changing during each washing cycle. The dependency of lanthanide solubility on nitric acid concentration is shown in Figure 3.7. The nitric acid concentration following each washing cycle is given by Equations 3.7, $3.8,3.9,3.10,3.11$ where $a$ is the fraction of slurry volume to slurry and wash volume and $b$ is the concentration of nitric acid in the wash solution. For wash solution equal in volume to the slurry volume, $a=0.5$. Figure 3.6 shows the predicted concentration of nitric acid and the reported concentration of nitric acid. Due to the discrepancies in analytical results, the predicted nitric acid concentrations are used for all correlations.

$$
\begin{gathered}
C_{H N O_{3}, 1}=a\left(C_{H N O_{3}, 0}+b\right) \\
C_{H N O_{3}, 2}=a\left(C_{H N O_{3}, 1}+b\right)=a\left(a C_{H N O_{3}, 0}+a b+b\right) \\
C_{H N O_{3}, 3}=a\left(C_{H N O_{3}, 2}+b\right)=a\left(a^{2} C_{H N O_{3}, 0}+a^{2} b+a b+b\right) \\
C_{H N O_{3}, 4}=a\left(C_{H N O_{3}, 3}+b\right)=a\left(a^{3} C_{H N O_{3}, 0}+a^{3} b+a^{2} b+a b+b\right) \\
C_{H N O_{3}, 5}=a\left(C_{H N O_{3}, 4}+b\right)=a\left(a^{4} C_{H N O_{3}, 0}+a^{4} b+a^{3} b+a^{2} b+a b+b\right)
\end{gathered}
$$

From Figure 3.7, the solubility of each lanthanide $(\mathrm{g} / \mathrm{L})$ is given by Equations $3.12,3.13,3.14,3.15,3.16$, and 3.17 .

$$
\begin{aligned}
& S_{E u, i}(i)=\left(1.4 \times 10^{-6}\right) \exp \left(8.2 C_{H N O_{3}, i}\right) \\
& S_{G d, i}(i)=\left(2.0 \times 10^{-6}\right) \exp \left(7.3 C_{H N O_{3, i}}\right)
\end{aligned}
$$




$$
\begin{aligned}
& S_{L a, i}(i)=\left(1.9 \times 10^{-5}\right) \exp \left(9.4 C_{H N O_{3}, i}\right) \\
& S_{N d, i}(i)=\left(6.4 \times 10^{-6}\right) \exp \left(8.5 C_{H N O_{3}, i}\right) \\
& S_{p r, i}(i)=\left(3.3 \times 10^{-6}\right) \exp \left(9.1 C_{H N O_{3}, i}\right) \\
& S_{S m, i}(i)=\left(1.3 \times 10^{-6}\right) \exp \left(8.4 C_{H N O_{3}, i}\right)
\end{aligned}
$$

Table 3.4 also shows the predicted concentrations of the lanthanide oxalates taking into account the change in oxalate solubility due to changes in nitric acid concentration.

\subsection{Effect of Washing Volume}

The volume of wash solution effects the washing efficiency of the system in that the nitric acid concentration changes with different wash volumes. The initial nitric acid concentration starts as approximately $1 \mathrm{M}$ and then decreases according to the wash volume used. The amount of wash volume used or the amount of initial supernate left in the tank effects how much of the metals are washed away at the expense of the lanthanide oxalates. The following derivations describe the percent separation of the metals and the percent retention of the lanthanides as a function of wash volume. The amount of material removed after each washing stage is equal to the volume removed multiplied by the concentration of each component. Equations 3.18, 3.19, 3.20, 3.21, and 3.22 describe how much of the metals are removed per cycle given a wash solution of $w$ gallons. For an equal volume wash, $w$ is the solution heel and the amount of wash solution added to the container. 3.785 is the conversion factor between liters and gallons.

$$
\begin{aligned}
& L_{F e, i}=3.785 w C_{F e, i}=15.14 w a^{i} \\
& L_{M n, i}=3.785 w C_{M n, i}=.757 w a^{i} \\
& L_{A l, i}=3.785 w C_{A l, i}=3.785 w a^{i} \\
& L_{n a, i}=3.785 w C_{n a, i}=1.1355 w a^{i} \\
& L_{C r, i}=3.785 w C_{C r, i}=.757 w a^{i}
\end{aligned}
$$

One must not forget that the first decant pulls off most of the metals. This loss is equal to the volume removed multiplied by the concentration of the initial supernate $S_{\text {Species }}$. For the demonstration carried out at TNX, the total volume was 26 gallons. This total volume represents the volume of the simulant plus 
the volume of the oxalic acid added for the precipitation. Equations 3.23-3.27 describe the amount of each metal (g) removed during the initial decant.

$$
\begin{aligned}
& f_{F e}=3.785(26-w) 4 \\
& f_{M n}=3.785(26-w) .2 \\
& f_{A l}=3.785(26-w) 1.0 \\
& f_{n a}=3.785(26-w) .3 \\
& f_{C r}=3.785(26-w) .2
\end{aligned}
$$

The sum of all metals removed during the initial decant and five washing stages is given in Equations 3.28-3.32.

$$
\begin{gathered}
S u m_{F e}=f_{F e}+\sum_{i=1}^{5} L_{F e, i}=393.64-.47313 w \\
S u m_{M n}=f_{M n}+\sum_{i=1}^{5} L_{M n, i}=19.682-2.3656 \times 10^{-2} w \\
S u m_{A l}=f_{A l}+\sum_{i=1}^{5} L_{A l, i}=98.41-.11828 w \\
S u m_{n a}=f_{n a}+\sum_{i=1}^{5} L_{n a, i}=29.523-3.5484 \times 10^{-2} w \\
S u m_{C r}=f_{C r}+\sum_{i=1}^{5} L_{C r, i}=19.682-2.3656 \times 10^{-2} w
\end{gathered}
$$

The percent separation is calculated as the fraction of metal removed relative to the metal content of the simulant solution by Equations 3.33-3.37.

$$
\begin{gathered}
\chi_{F e}=\frac{f_{F e}+\sum_{i=1}^{5} L_{F e, i}}{3.785(26) 4}=1.0-1.2019 \times 10^{-3} w \\
\chi_{M n}=\frac{f_{M n}+\sum_{i=1}^{5} L_{M n, i}}{3.785(26) 0.2}=1.0-1.2019 \times 10^{-3} w
\end{gathered}
$$




$$
\begin{gathered}
\chi_{A l}=\frac{f_{A l}+\sum_{i=1}^{5} L_{A l, i}}{3.785(26)}=1.0-1.2019 \times 10^{-3} w \\
\chi_{n a}=\frac{f_{n a}+\sum_{i=1}^{5} L_{n a, i}}{3.785(26) 0.3}=1.0-1.2019 \times 10^{-3} w \\
\chi_{C r}=\frac{f_{C r}+\sum_{i=1}^{5} L_{C r, i}}{3.785(26) 0.2}=1.0-1.2019 \times 10^{-3} w
\end{gathered}
$$

The percent separation decreases with increasing solution heel, because increasing the wash volume implies that less material is decanted before the washing cycles occur. Figure 3.3 shows percent separation as a function of wash volume in gallons. Zero wash volume implies that all the supernate is removed during the first decant. Removing all of the supernate takes all of the metal oxalates with it.

The lanthanide losses $(\mathrm{g})$ are calculated by taking the wash volume and multiplying it by the solubility of each lanthanide. Equations 3.38-3.43 describe the grams of lanthanide loss during each washing cycle as a function of the wash volume in gallons.

$$
\begin{aligned}
& L_{E u, i}(i)=3.785 w S_{E u, i} \\
& L_{G d, i}(i)=3.785 w S_{G d, i} \\
& L_{L a, i}(i)=3.785 w S_{L a, i} \\
& L_{N d, i}(i)=3.785 w S_{N d, i} \\
& L_{p r, i}(i)=3.785 w S_{p r, i} \\
& L_{S m, i}(i)=3.785 w S_{S m, i}
\end{aligned}
$$

The lanthanide oxalates are also removed during the first decant prior to washing. Equations 3.44-3.49 describe the loss of lanthanide oxalates $(\mathrm{g})$ during the first decant as a function of wash volume.

$$
f_{E u}=3.785(26-w)\left(1.4 \times 10^{-6}\right) \exp \left(8.2 C_{H_{N O}, 0}\right)
$$




$$
\begin{gathered}
f_{G d}=3.785(26-w)\left(2.0 \times 10^{-6}\right) \exp \left(7.3 C_{H N O_{3}, 0}\right) \\
f_{L a}=3.785(26-w)\left(1.9 \times 10^{-5}\right) \exp \left(9.4 C_{H N O_{3}, 0}\right) \\
f_{N d}=3.785(26-w)\left(6.4 \times 10^{-6}\right) \exp \left(8.5 C_{H N O_{3}, 0}\right) \\
f_{p r}=3.785(26-w)\left(3.3 \times 10^{-6}\right) \exp \left(9.1 C_{H N O_{3}, 0}\right) \\
f_{S m}=3.785(26-w)\left(1.3 \times 10^{-6}\right) \exp \left(8.4 C_{H N O_{3}, 0}\right)
\end{gathered}
$$

The sum of lanthanide losses for both decant and washing is shown below as a function of wash volume in gallons.

$$
\begin{array}{r}
S u m_{E u}=\left(\sum_{i=1}^{5} L_{E u, i}\right)+f_{E u}=-4.8946 \times 10^{-3} w+.22093 \\
S u m_{G d}=\left(\sum_{i=1}^{5} L_{G d, i}\right)+f_{G d}=-2.4535 \times 10^{-3} w+.14041 \\
\operatorname{Sum}_{L a}=\left(\sum_{i=1}^{5} L_{L a, i}\right)+f_{L a}=-.23598 w+8.8293 \\
S u m_{N d}=\left(\sum_{i=1}^{5} L_{N d, i}\right)+f_{N d}=-.03103 w+1.323 \\
S u m_{p r}=\left(\sum_{i=1}^{5} L_{p r, i}\right)+f_{p r}=-3.0122 \times 10^{-2} w+1.1706 \\
S_{S u m_{S m}}=\left(\sum_{i=1}^{5} L_{S m, i}\right)+f_{S m}=-5.6573 \times 10^{-3} w+.24561
\end{array}
$$

The percent retention of lanthanides is calculated based on the initial amount of lanthanide present.

$$
\chi_{E u}=\frac{3.785(16) 0.577-\left(f_{E u}+\sum_{i=1}^{5} L_{E u, i}\right)}{3.785(16) 0.577}=.99368+1.4007 \times 10^{-4} w
$$




$$
\begin{gathered}
\chi_{G d}=\frac{3.785(16) 0.409-\left(f_{G d}+\sum_{i=1}^{5} L_{G d, i}\right)}{3.785(16) 0.409}=.99433+9.9056 \times 10^{-5} w \\
\chi_{L a}=\frac{3.785(16) 0.93-\left(f_{L a}+\sum_{i=1}^{5} L_{L a, i}\right)}{3.785(16) 0.93}=.84323+.00419 w \\
\chi_{N d}=\frac{3.785(16) 1.42-\left(f_{N d}+\sum_{i=1}^{5} L_{N d, i}\right)}{3.785(16) 1.42}=.98461+3.6084 \times 10^{-4} w
\end{gathered}
$$

$$
\chi_{p r}=\frac{3.785(16) 1.01-\left(f_{p r}+\sum_{i=1}^{5} L_{p r, i}\right)}{3.785(16) 1.01}=.98086+4.9246 \times 10^{-4} w
$$

$$
\chi_{S m}=\frac{3.785(16) 0.547-\left(f_{S m}+\sum_{i=1}^{5} L_{S m, i}\right)}{3.785(16) 0.547}=.99259+1.7078 \times 10^{-4} w
$$

The average lanthanide retention is represented by the following equation. Notice that the retention of lanthanides increases as the wash volume or solution heel increases. A larger wash volume implies less of the original solution is decanted prior to washing. The nitric acid concentration is highest in the original solution, and more of the lanthanides are soluble at that time. Figure 3.3 shows the percent retention of lanthanides versus the percent removal of the metals all as a function of wash volume for the 26 gallon demonstration carried out at TNX.

$$
T=\frac{\chi_{E u}+\chi_{G d}+\chi_{L a}+\chi_{p r}+\chi_{S m}+\chi_{N d}}{6}=.96488+1.7924 \times 10^{-3} w
$$

The lanthanum oxalate solubility decreases the average retention. The solubility of lanthanum oxalate via mass spectrometer is pending. The average retention of the lanthanide oxalates would be $>99 \%$ if it were not for the lanthanum oxalate. 


\begin{tabular}{|c|c|c|c|c|}
\hline Time (min) & Volume (m) & Volume (ml) & Volume (ml) & Volume (ml) \\
\hline \hline 0 & 2020 & 2020 & 2020 & 2020 \\
\hline 1 & 1940 & 1940 & 1940 & 1900 \\
\hline 2 & 1880 & 1860 & 1860 & 1870 \\
\hline 3 & 1800 & 1800 & 1800 & 1770 \\
\hline 4 & 1720 & 1720 & 1720 & 1700 \\
\hline 5 & 1640 & 1640 & 1640 & 1630 \\
\hline 8 & 1420 & 1420 & 1420 & 1410 \\
\hline 10 & 1230 & 1220 & 1260 & 1240 \\
\hline 12 & & 1100 & 1090 & 1090 \\
\hline 15 & 1020 & 1020 & 1020 & 1020 \\
\hline 18 & 1020 & 1020 & 1020 & 1020 \\
\hline 20 & 1020 & 1020 & 1020 & 1020 \\
\hline
\end{tabular}

Table 3.1: Volume of heavy particles as a function of time for 4 tests.

\begin{tabular}{|c|c|c|c|c|}
\hline Time (min) & Volume (m) & Volume (ml) & Volume (ml) & Volume (ml) \\
\hline \hline 0 & 2020 & 2020 & 2020 & 2020 \\
\hline 1 & & & & 1920 \\
\hline 2 & & 1900 & 1920 & 1920 \\
\hline 3 & & 1840 & 1880 & 1860 \\
\hline 4 & & 1820 & 1820 & 1820 \\
\hline 5 & & 1790 & 1780 & 1780 \\
\hline 8 & 1620 & 1620 & 1640 & 1620 \\
\hline 10 & 1520 & 1500 & 1540 & 1520 \\
\hline 12 & & 1400 & 1420 & 1410 \\
\hline 15 & 1280 & 1260 & 1260 & 1300 \\
\hline 18 & & & 1050 & 1220 \\
\hline 20 & 1020 & 1020 & 1020 & 1020 \\
\hline
\end{tabular}

Table 3.2: Volume of intermediate particles as a function of time for 4 tests.

\begin{tabular}{|c|c|c|}
\hline Time (min) & Volume (ml) & Volume (m) \\
\hline \hline 0 & 2020 & 2020 \\
\hline 60 & 1980 & 1900 \\
\hline 155 & 1300 & 1700 \\
\hline 215 & no discernable layer & no discernable layer \\
\hline
\end{tabular}

Table 3.3: Volume of smallest particles as a function of time for 2 tests. The distinction between the clear supernate and fines was evident until approximately four hours into the test. At that point, the supernate remained slightly coudly. 


\begin{tabular}{|c|c|c|c|c|c|c|}
\hline & $\begin{array}{l}\mathbf{L a} \\
\mathrm{g} / \mathrm{L}\end{array}$ & $\begin{array}{l}\mathbf{P r} \\
\mathrm{g} / \mathrm{L}\end{array}$ & $\begin{array}{l}\text { Nd } \\
\mathrm{g} / \mathrm{L}\end{array}$ & $\begin{array}{l}\text { Sm } \\
\mathrm{g} / \mathrm{L}\end{array}$ & $\begin{array}{l}\mathbf{E u} \\
\mathrm{g} / \mathbf{L}\end{array}$ & $\begin{array}{l}\text { Gd } \\
\text { g/L }\end{array}$ \\
\hline \multicolumn{7}{|l|}{ Simulant } \\
\hline \multirow{2}{*}{$\begin{array}{l}\text { Makeup } \\
\text { Analysis }\end{array}$} & 0.875 & 1.00 & 1.7 & 0.50 & 0.58 & 0.40 \\
\hline & 0.930 & 1.01 & 1.7 & 0.55 & 0.58 & 0.41 \\
\hline \multirow{2}{*}{$\begin{array}{l}\text { Supernate } \\
\text { Analysis }\end{array}$} & & & & & & \\
\hline & .0823 & .0149 & .0145 & .00265 & .00206 & .00152 \\
\hline \multicolumn{7}{|l|}{ 1st Wash } \\
\hline \multirow{2}{*}{$\begin{array}{l}\text { Analysis } \\
\text { Predict }\end{array}$} & .0231 & .0020 & .0031 & $6.45 \times 10^{-4}$ & $6.45 \times 10^{-4}$ & $4.13 \times 10^{-4}$ \\
\hline & .01369 & $1.92 \times 10^{-3}$ & $2.46 \times 10^{-3}$ & $4.65 \times 10^{-4}$ & $4.35 \times 10^{-4}$ & $3.31 \times 10^{-4}$ \\
\hline \multirow{3}{*}{$\begin{array}{l}\text { 2nd Wash } \\
\text { Analysis } \\
\text { Predict }\end{array}$} & & & & & & \\
\hline & .00839 & $6.04 \times 10^{-4}$ & .00127 & $2.7 \times 10^{-4}$ & $2.58 \times 10^{-4}$ & $1.96 \times 10^{-4}$ \\
\hline & .00535 & $7.76 \times 10^{-4}$ & $1.05 \times 10^{-3}$ & $2.01 \times 10^{-4}$ & $1.92 \times 10^{-4}$ & $1.60 \times 10^{-4}$ \\
\hline \multirow{3}{*}{$\begin{array}{l}\text { 3rd Wash } \\
\text { Analysis } \\
\text { Predict }\end{array}$} & & & & & & \\
\hline & .00412 & $5.02 \times 10^{-4}$ & $8.55 \times 10^{-4}$ & $1.96 \times 10^{-4}$ & $1.83 \times 10^{-4}$ & $1.53 \times 10^{-4}$ \\
\hline & .00334 & $4.92 \times 10^{-4}$ & $6.86 \times 10^{-4}$ & $1.32 \times 10^{-4}$ & $1.27 \times 10^{-4}$ & $1.11 \times 10^{-4}$ \\
\hline \multirow{3}{*}{$\begin{array}{l}\text { 4th Wash } \\
\text { Analysis } \\
\text { Predict }\end{array}$} & & & & & & \\
\hline & .00284 & $6.09 \times 10^{-4}$ & $7.32 \times 10^{-4}$ & $1.49 \times 10^{-4}$ & $1.32 \times 10^{-4}$ & $1.5 \times 10^{-4}$ \\
\hline & .00264 & $3.92 \times 10^{-4}$ & $5.55 \times 10^{-4}$ & $1.07 \times 10^{-4}$ & $1.04 \times 10^{-4}$ & $9.24 \times 10^{-5}$ \\
\hline \multirow{3}{*}{$\begin{array}{l}\text { 5th Wash } \\
\text { Analysis } \\
\text { Predict }\end{array}$} & & & & & & \\
\hline & .0027 & $6.6 \times 10^{-4}$ & $6.36 \times 10^{-4}$ & $1.0 \times 10^{-4}$ & $8.74 \times 10^{-5}$ & $9.0 \times 10^{-5}$ \\
\hline & .0024 & $3.5 \times 10^{-4}$ & $4.99 \times 10^{-4}$ & $9.63 \times 10^{-5}$ & $9.36 \times 10^{-5}$ & $8.43 \times 10^{-5}$ \\
\hline
\end{tabular}

Table 3.4: The solubility of the lanthanides is recorded during each phase of the demonstration. Predicted lanthanide concentrations are based on the nitric acid-solubility of the lanthanides and a 5 gallon wash. 


\begin{tabular}{|c|c|c|c|c|c|c|}
\hline & $\begin{array}{c}\text { Al } \\
g / L\end{array}$ & $\begin{array}{l}\mathrm{Ca} \\
\mathrm{g} / \mathrm{L}\end{array}$ & $\begin{array}{l}\text { Fe } \\
\text { g/L }\end{array}$ & $\begin{array}{l}\mathrm{Mn} \\
\mathrm{g} / \mathrm{L}\end{array}$ & $\begin{array}{l}\text { Na } \\
\text { g/L }\end{array}$ & $\begin{array}{c}\text { Cr } \\
\text { g/L }\end{array}$ \\
\hline \multicolumn{7}{|l|}{ Simulant } \\
\hline \multirow{2}{*}{$\begin{array}{l}\text { Makeup } \\
\text { Analysis }\end{array}$} & 1.34 & 0.083 & 6.19 & 0.30 & 0.84 & 0.36 \\
\hline & 1.49 & 0.103 & 6.48 & 0.32 & 0.55 & 0.39 \\
\hline \multirow{3}{*}{$\begin{array}{l}\text { Supernate } \\
\text { Analysis } \\
\text { Predict }\end{array}$} & & & & & & \\
\hline & .882 & .0509 & 4.10 & .185 & .324 & .216 \\
\hline & .917 & .0634 & 3.99 & .197 & .338 & .24 \\
\hline \multirow{3}{*}{$\begin{array}{l}\text { 1st Wash } \\
\text { Analysis } \\
\text { Model }\end{array}$} & & & & & & \\
\hline & .228 & .0133 & 1.06 & .049 & .0865 & .0584 \\
\hline & .441 & .255 & 2.05 & .0925 & .162 & .108 \\
\hline \multirow{3}{*}{$\begin{array}{l}\text { 2nd Wash } \\
\text { Analysis } \\
\text { Model }\end{array}$} & & & & & & \\
\hline & .149 & .00859 & .67 & .0309 & .0576 & .0394 \\
\hline & .221 & .0127 & 1.025 & .04625 & .081 & .054 \\
\hline \multirow{3}{*}{$\begin{array}{l}\text { 3rd Wash } \\
\text { Analysis } \\
\text { Model }\end{array}$} & & & & & & \\
\hline & .063 & .00364 & .282 & .0125 & .0225 & .0156 \\
\hline & .11 & .00636 & .513 & .0231 & .0405 & .027 \\
\hline \multirow{3}{*}{$\begin{array}{l}\text { 4th Wash } \\
\text { Analysis } \\
\text { Model }\end{array}$} & & & & & & \\
\hline & .026 & .0015 & .118 & .00538 & .00965 & .00666 \\
\hline & .0551 & .00318 & .256 & .0116 & .02025 & .0135 \\
\hline \multirow{3}{*}{$\begin{array}{l}\text { 5th Wash } \\
\text { Analysis } \\
\text { Model }\end{array}$} & & & & & & \\
\hline & .00593 & 0.000361 & .0254 & .00112 & .00211 & .00142 \\
\hline & .0276 & .00159 & .128 & .00578 & 0.0101 & .00675 \\
\hline
\end{tabular}

Table 3.5: The solubility of the metal oxalates is measured at each stage in the demonstration. 
Total Solids, Soluble Solids, and Insoluble Solids During Settling

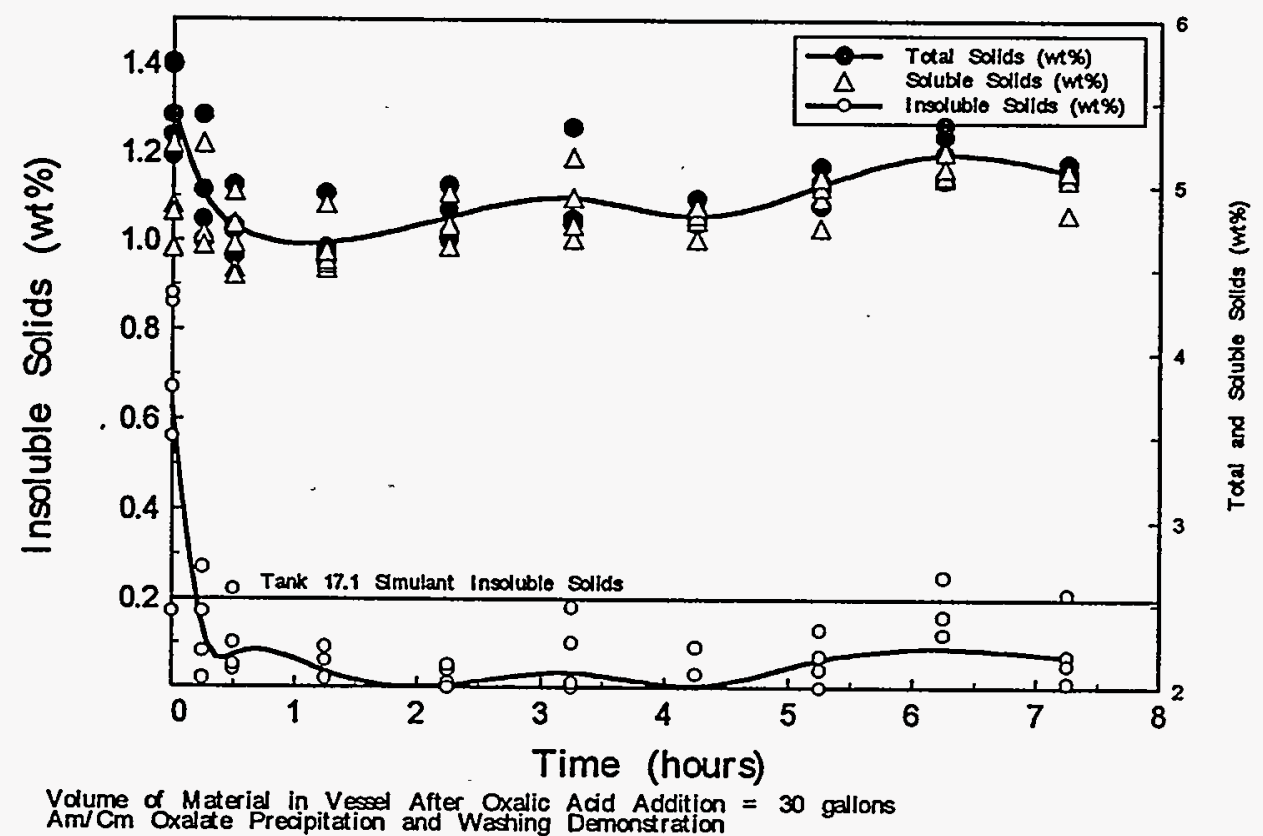

Figure 3.1: Total solids, insoluble solids, and soluble solids during the settling stage of the demonstration. The insoluble solids settled in the first 30 minutes of the eight hour period. 


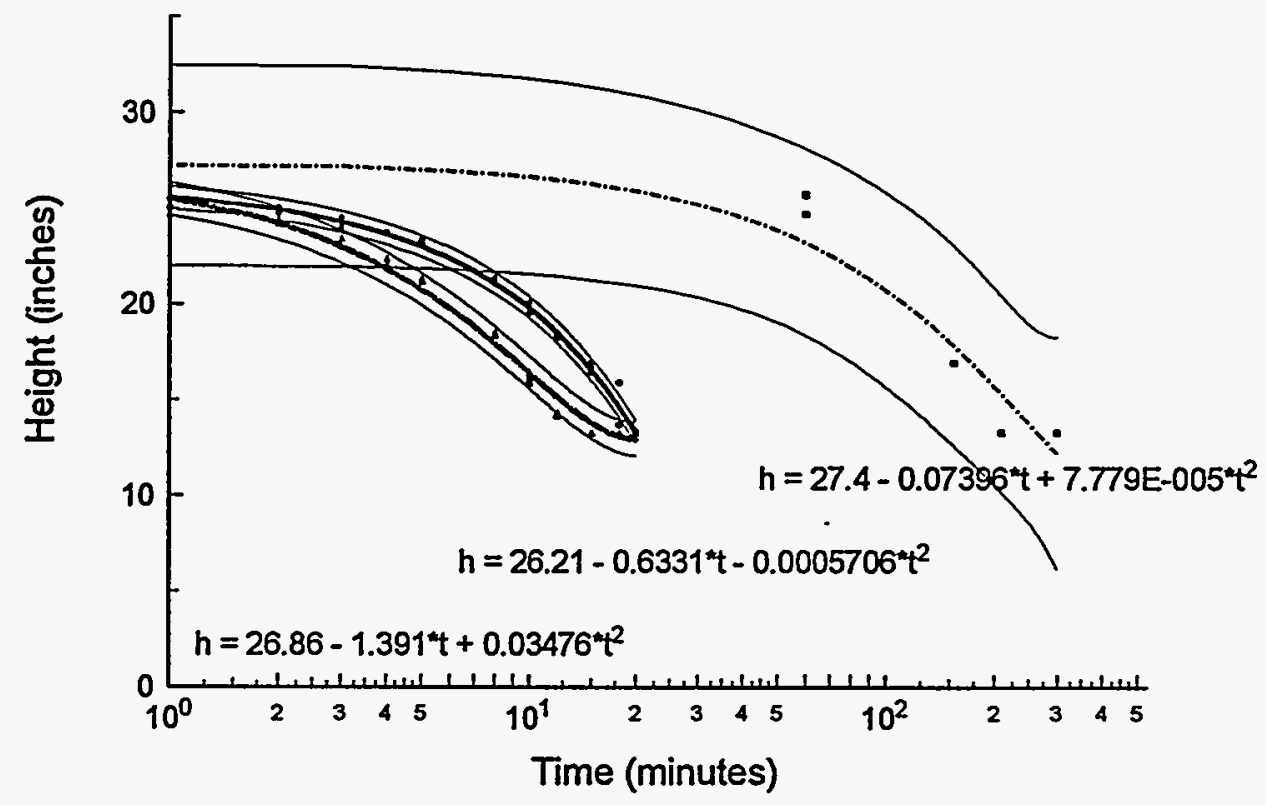

Figure 3.2: The height of the solid liquid interface (in a $2 \mathrm{~L}$ graduated cyliner) is plotted versus time for each of the three particle size distributions in the oxalate precipitate. The large and intermediate sized particles fall out of solution within 20 minutes, and the smallest particles remain in solution for approximately 14 hours. Each line is surrounded by the $95 \%$ confidence on the regression analysis. 
Separation Efficiency of Metals and Retention of Lanthanides as a function of Slurny or Wash Volume

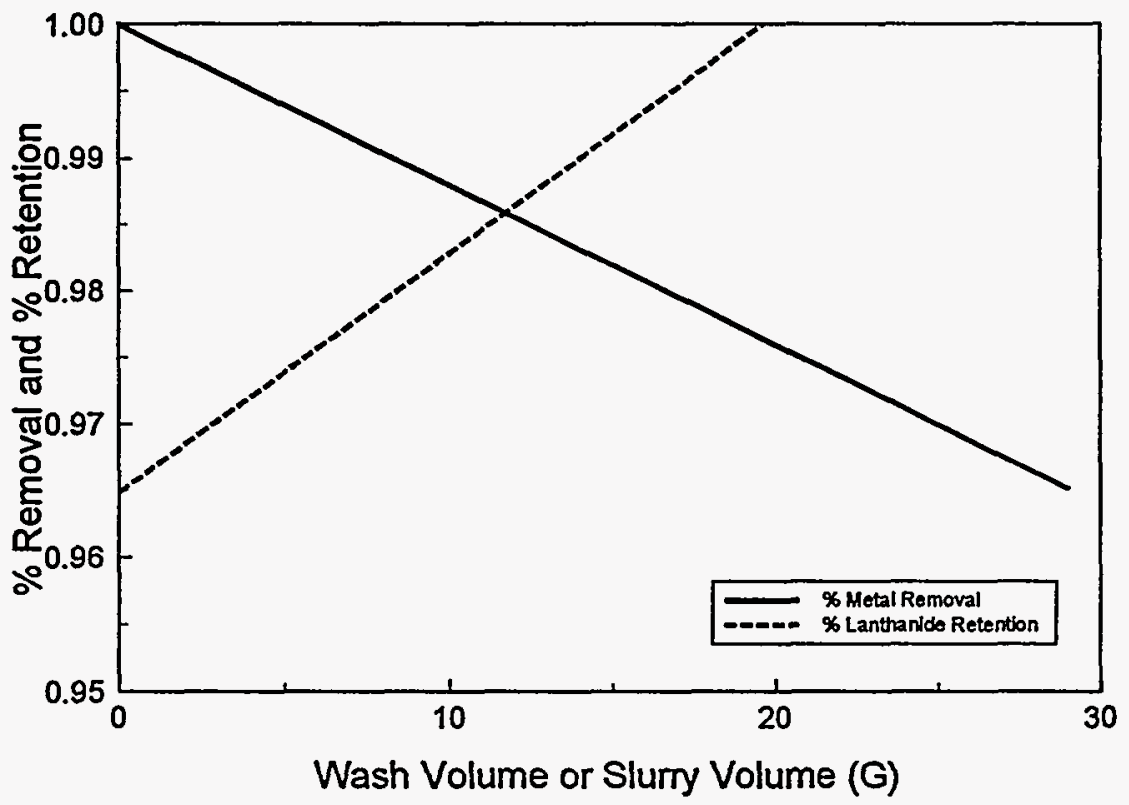

Figure 3.3: Metal removal efficiency and lanthanide retention as a function of wash volume. 
Supemate lon Concentration of Various Lanthanides

During Washing

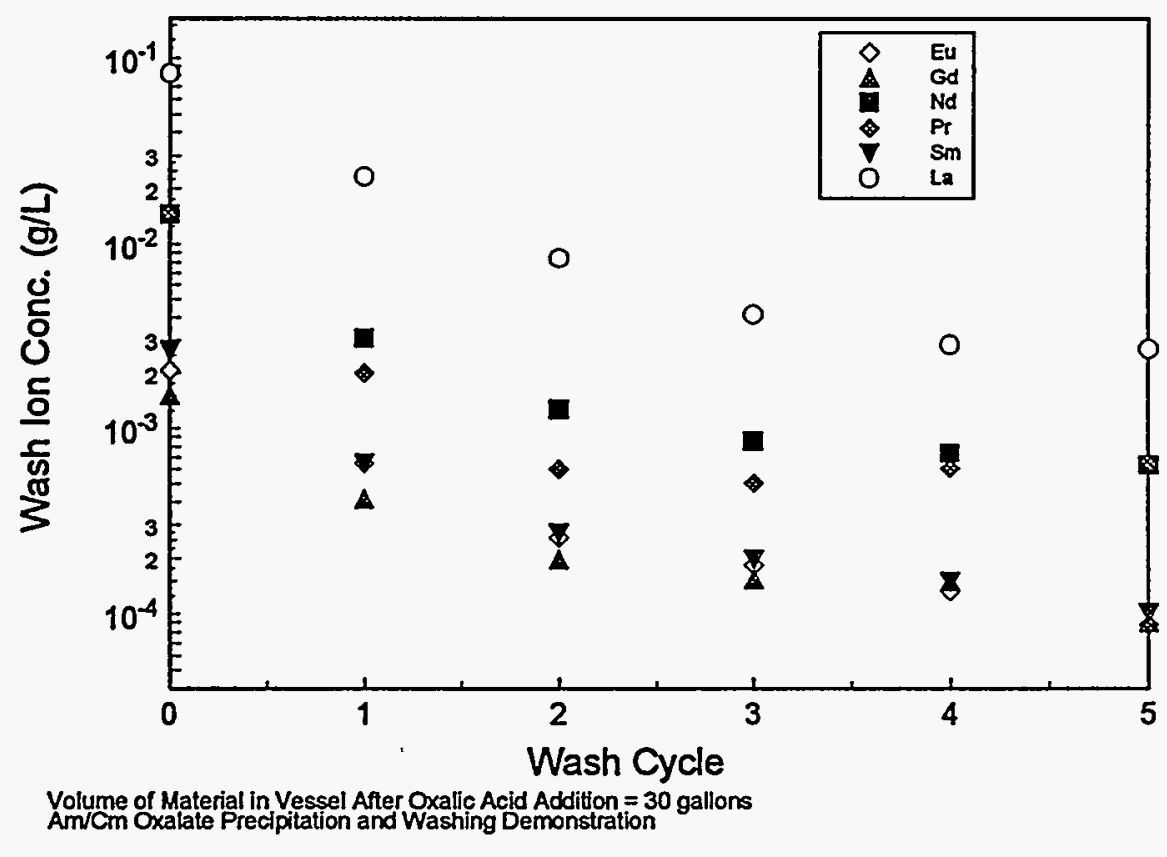

Figure 3.4: Lanthanide concentrations as a function of wash cycle. Cylce 0 is the supernate concentration of the first decant. 


\section{Supernate Ion Density of Various Metals} During Washing

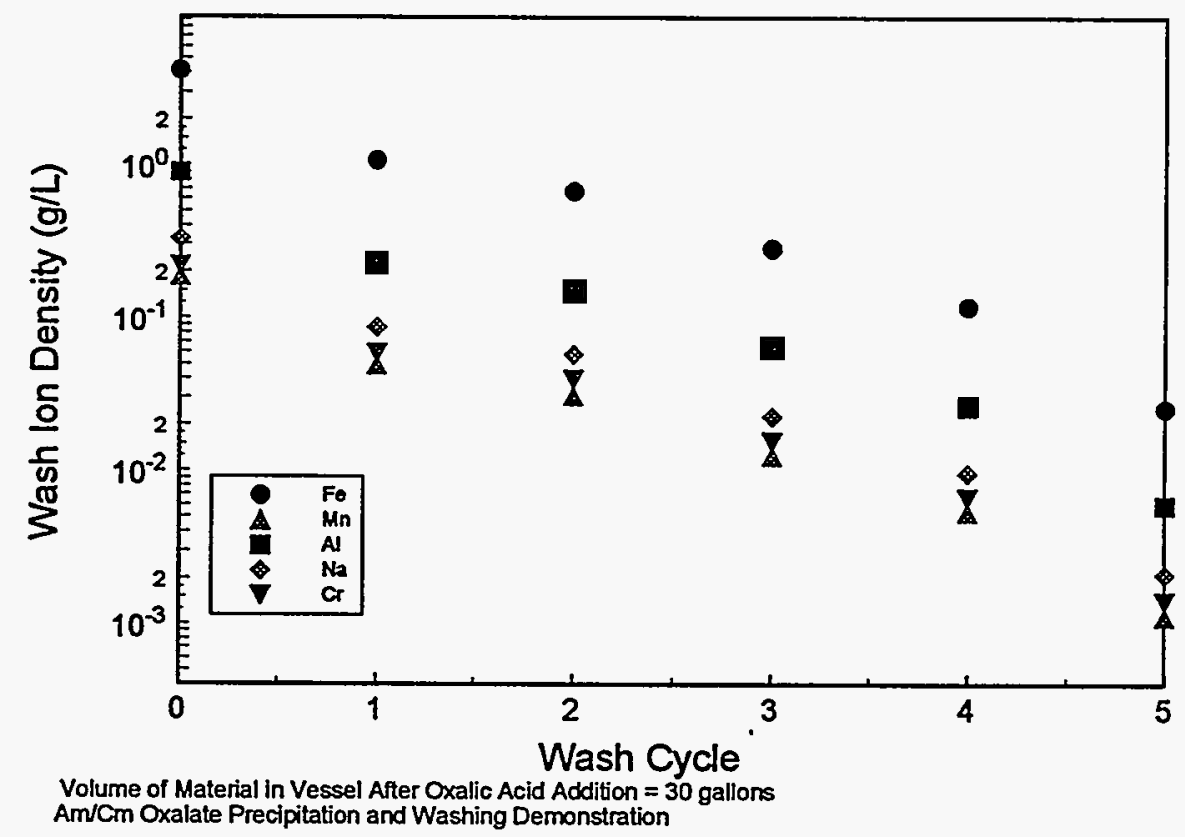

Figure 3.5: Metal concentrations as a function of wash cycle. Cycle 0 represents the initial decant supernate. 


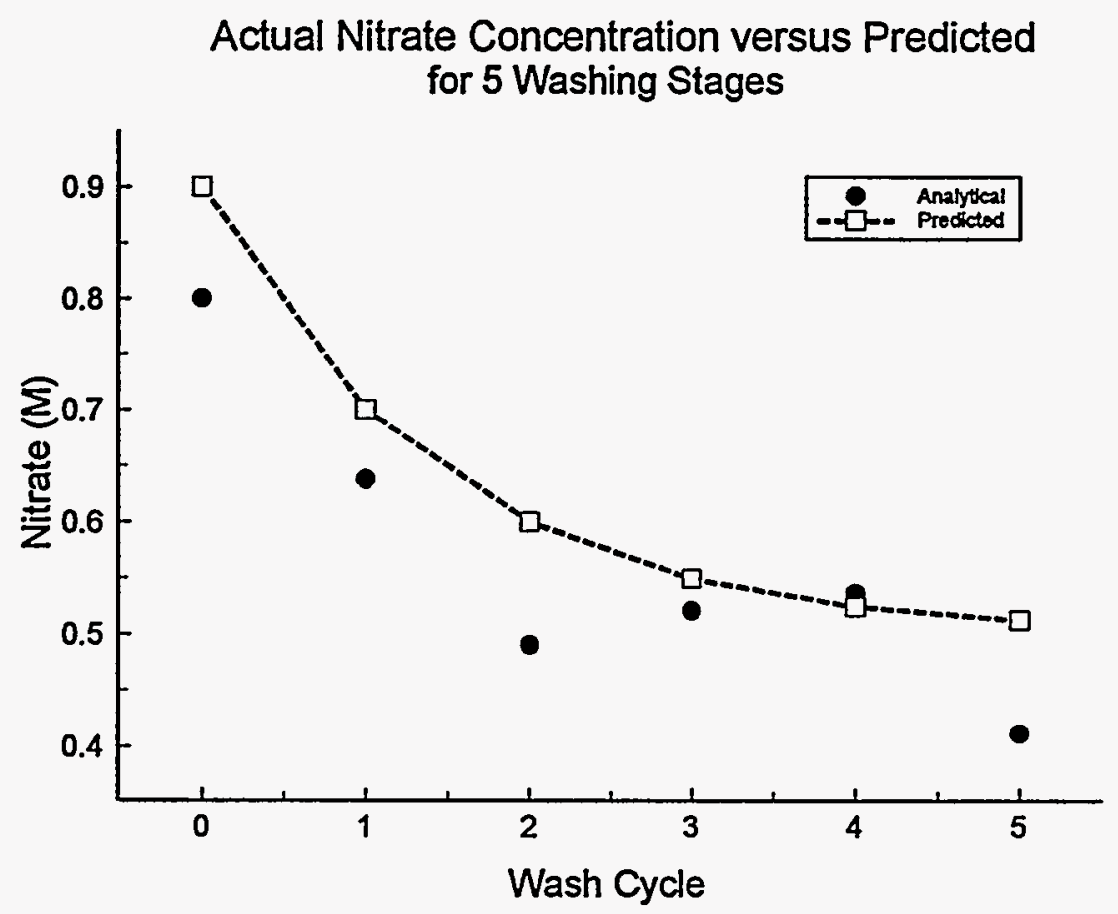

Figure 3.6: Nitric acid concentration following each wash cycle compared with the washing model. This figure shows the inablity of analytical to accurately determine the anion concentrations. The solubility dependence on nitric acid concentration will use the washing model nitric acid concentration. 


\section{Supernate Ion Concentration of Various Lanthanides During Washing}

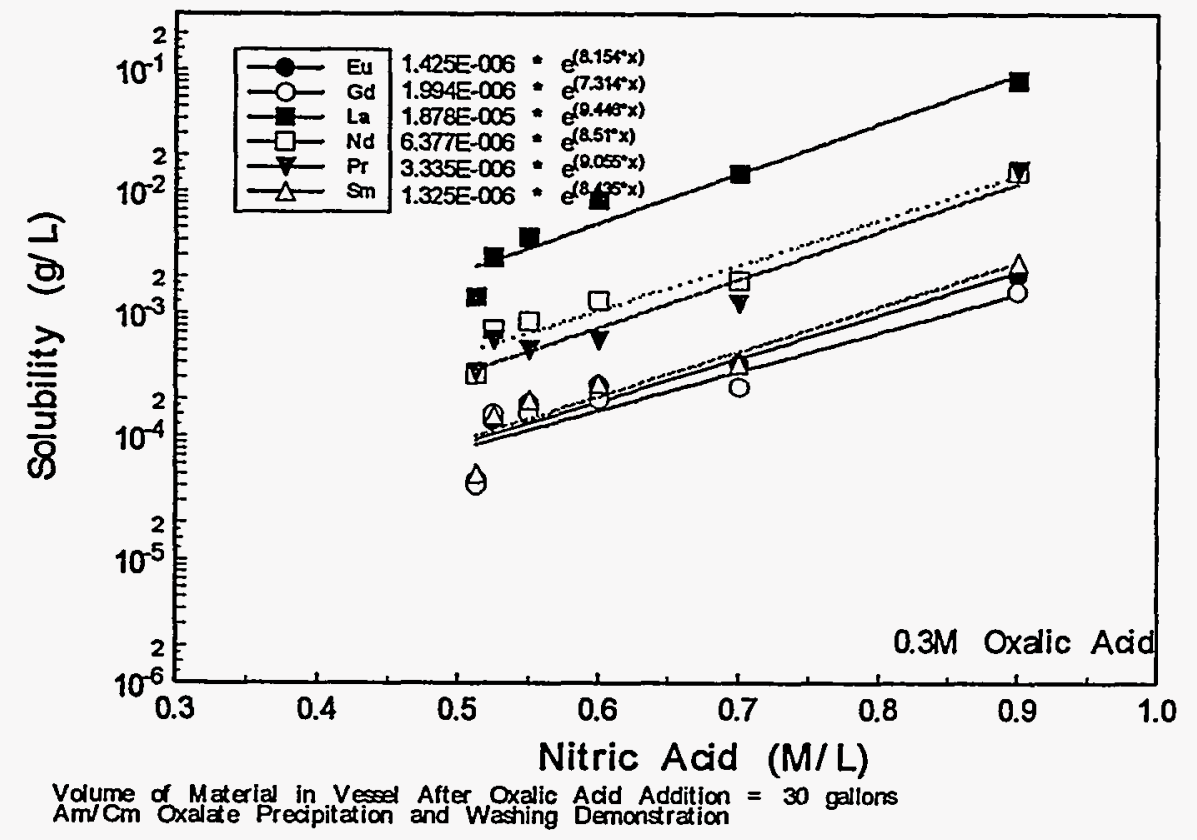

Figure 3.7: Lanthanide solubilities as a function of nitric acid concentration. The oxalic acid concentration remained $0.3 \mathrm{M}$ after the digestion stage. 


\section{Chapter 4}

\section{Discussion}

These results provide insight into the processing required for separation of the lanthanide/actinides from the metals. First, the reported lanthanide/actinide content of Tank 17.1 is 600 moles. Using $0.5 \mathrm{~L} / \mathrm{mole}$ of lanthanide/actinide yields $300 \mathrm{~L}$ of solid precipitate, and dispersing this volume in the processing tank (E.P.\# 221-H-20322-B) predicts approximately a 3 inch layer on the bottom of the tank. A 3 inch slurry layer will not reach the bottom of the lowest coil in the vessel. It is $\mathbf{5}$ inches from the bottom of the vessel to the centerline of the 2 inch coil. Second, the settling tests reveal that the lanthanide oxalates settle within 30 minutes. Third, the location of the dip tube determines the amount of supernate removed during the first decant and therefore the percent lanthanide retention and the percent metal removal. Placing the dip tube at the solid/liquid interface (small solution heels) removes the metals $(100 \%)$ at the expense of the slightly soluble lanthanide oxalates (3.5\%) assuming no solids entrainment. Neglecting the first decant and performing an equal volume wash (using large solution heels) reduces the lanthanide losses (0\%) at the expense of metal retention (4\%) and volume generation. In conclusion, the slurry specific volume and the settling rate of the precipitate have been established with both bench scale and pilot scale experiments, but the desired compromise among metal oxalate removal, lanthanide oxalate retention, and waste generation has not been established to allow dip tube placement design.

\subsection{Maximizing Lanthanide Retention}

Maximizing the lanthanide retention percentage is a function of wash volume as shown by Figure 3.3. In order to increase performance, it might be interesting to determine which process variables have the most impact on the percent retention of the lanthanide/actinides. Equation 3.50 is shown here to describe the loss of europium in the first decant and five wash cycles. 


$$
S u m_{E u}=\left(\sum_{i=1}^{5} L_{E u, i}(i)\right)+f_{E u}
$$

Expanding this equation into its corresponding variables show that the loss of europium is dependent upon the starting nitric acid concentration, the wash volume, and the wash solution nitric acid concentration. Keep in mind that this equation is for wash solution that is equal in volume to the slurry is only valid for equal volumes of solution heel to wash solution.

$$
\begin{aligned}
\operatorname{Sum}_{E u}= & 5.299 \times 10^{-6} w \exp \left(4.1 C_{H N O_{3}, 0}+4.1 b\right)+ \\
& 5.299 \times 10^{-6} w \exp \left(2.05 C_{H N O_{3}, 0}+6.15 b\right)+ \\
& 5.299 \times 10^{-6} w \exp \left(1.025 C_{H N O_{3}, 0}+7.175 b\right)+ \\
& 5.299 \times 10^{-6} w \exp \left(.5125 C_{H N O_{3}, 0}+7.6875 b\right)+ \\
& 5.299 \times 10^{-6} w \exp \left(.25625 C_{H N O_{3}, 0}+7.9438 b\right)+ \\
& 1.3777 \times 10^{-4} \exp \left(8.2 C_{H N O_{3}, 0}\right)- \\
& 5.299 \times 10^{-6} \exp \left(8.2 C_{H N O_{3}, 0}\right) w
\end{aligned}
$$

The slope of the loss line with respect to the wash volume, Equation 4.2 , is controlled by the concentrations of nitric acid in the original solution and the wash solution. The intercept is controlled by the concentration of the original nitric acid solution. Therefore, to decrease the rate at which lanthanides are loss as a function of wash volume, the starting nitric acid and wash nitric acid concentration should be minimized. Figure 4.1 plots Equation 4.2 as a function of wash nitric concentration and initial nitric acid concentration. One can clearly see that the rate of loss, $D(b, C)$, increases as the two nitric acid concentrations increase.

$$
\begin{aligned}
& \frac{d\left(\left(\sum_{i=1}^{5} L_{E u, i}(i)\right)+f_{E u}\right)}{d w}=5.299 \times 10^{-6} \exp \left(4.1 C_{H N O_{3}, 0}+4.1 b\right)+ \\
& 5.299 \times 10^{-6} \exp \left(2.05 C_{H_{N O}, 0}+6.15 b\right)+ \\
& 5.299 \times 10^{-6} \exp \left(1.025 C_{H_{N O}, 0}+7.175 b\right)+ \\
& 5.299 \times 10^{-6} \exp \left(.5125 \mathrm{C}_{\mathrm{HNO}_{3}, \mathrm{O}}+7.6875 b\right)+ \\
& 5.299 \times 10^{-6} \exp \left(.25625 C_{H N O_{s}, 0}+7.9438 b\right)- \\
& 5.299 \times 10^{-6} \exp \left(8.2 C_{H N O_{3}, 0}\right)
\end{aligned}
$$

$$
\begin{aligned}
D(b, C)= & 5.299 \times 10^{-6} \exp (4.1 C+4.1 b)+5.299 \times 10^{-6} \exp (2.05 C+6.15 b)+ \\
& 5.299 \times 10^{-6} \exp (1.025 C+7.175 b)+5.299 \times 10^{-6} \exp (.5125 C+7.6875 b)+ \\
& 5.299 \times 10^{-6} \exp (.25625 C+7.9438 b)-5.299 \times 10^{-6} \exp (8.2 C)
\end{aligned}
$$




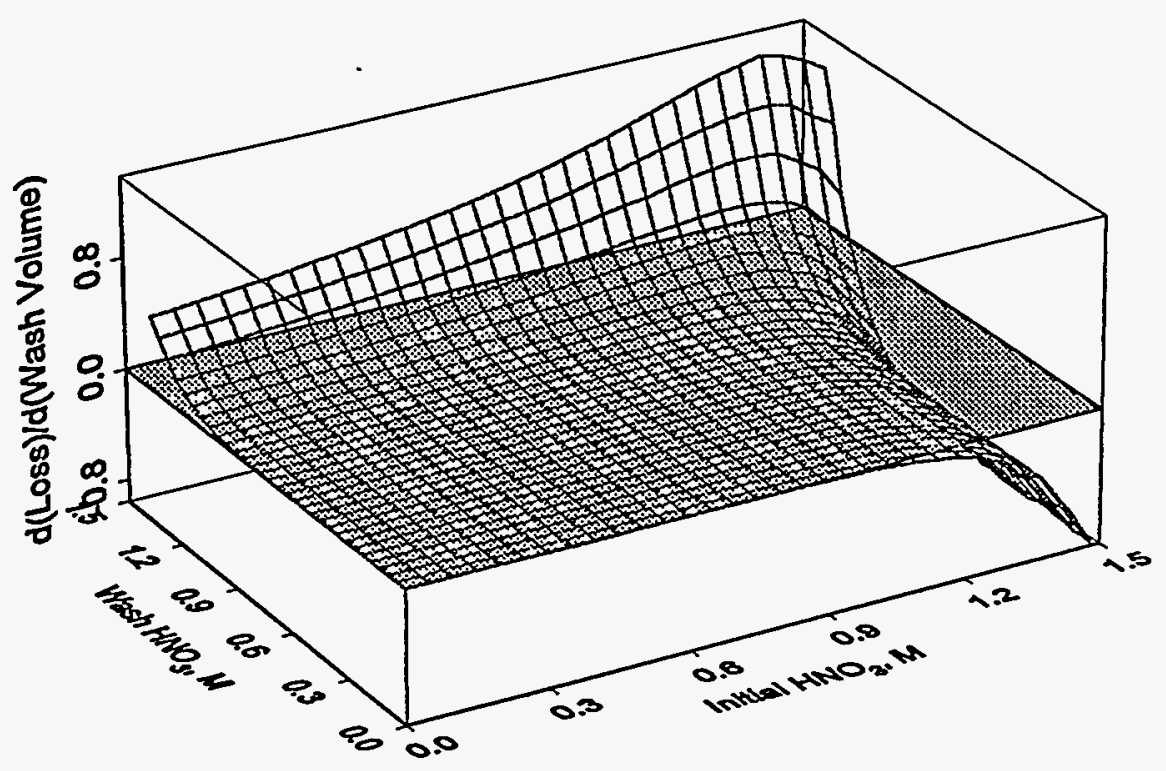

Figure 4.1: Rate of loss of Eu with wash volume as a function of intitial nitric acid concentration and wash nitric acid concentration.

Figure 4.1 shows that increasing nitric acid concentration in both the initial solution and wash solution will increase the tendency of the losing lanthanides with increasing wash volumes. This figure also shows the relative insensitivity of the loss equation, 4.2, to changes in nitric acid concentrations at the processing conditions of this demonstration. The retention of lanthanides, as a function of wash volume in Figure 3.3, is not expected to change with reasonable changes in processing conditions. 


\section{Chapter 5}

\section{Appendix}

.1 Constants for Derivations

$$
\begin{gathered}
a=0.5 \\
b=0.5 \\
w=6 \\
C_{H N O_{3}, 0}=0.9 \\
a=0.5 \\
V=16 \\
\omega_{F e}=56 \\
\omega_{M n}=55 \\
\omega_{A l}=27 \\
\omega_{n a}=23 \\
\omega_{C r}=52
\end{gathered}
$$

\section{.2 Sampling Protocol}




\begin{tabular}{|l|l|l|l|l|l|}
\hline Situation & $\# 1$ & \#2 & \#3 & \#4 & \#5 \\
\hline \hline Simulant & $3^{\prime \prime}$ & $3^{\prime \prime}$ & $3^{\prime \prime}$ & $3^{\prime \prime}$ & $3^{\prime \prime}$ \\
\hline Digestion $t=0.0 \mathrm{hr}$ & $3^{\prime \prime}$ & $3^{\prime \prime}$ & $3^{\prime \prime}$ & $3^{\prime \prime}$ & $3^{\prime \prime}$ \\
\cline { 2 - 6 } Digestion $t=1.0 \mathrm{hr}$ & $3^{\prime \prime}$ & $3^{\prime \prime}$ & $3^{\prime \prime}$ & $3^{\prime \prime}$ & $3^{\prime \prime}$ \\
\cline { 2 - 6 } Digestion $t=2.0 \mathrm{hr}$ & $3^{\prime \prime}$ & $3^{\prime \prime}$ & $3^{\prime \prime}$ & $3^{\prime \prime}$ & $3^{\prime \prime}$ \\
\cline { 2 - 6 } Digestion $t=2.5 \mathrm{hr}$ & $3^{\prime \prime}$ & $3^{\prime \prime}$ & $3^{\prime \prime}$ & $3^{\prime \prime}$ & $3^{\prime \prime}$ \\
\cline { 2 - 6 } Digestion $t=3.0 \mathrm{hr}$ & $3^{\prime \prime}$ & $3^{\prime \prime}$ & $3^{\prime \prime}$ & $3^{\prime \prime}$ & $3^{\prime \prime}$ \\
\hline Settling $t=0 \mathrm{hr}$ & $0^{\prime \prime}$ & $1^{\prime \prime}$ & $2^{\prime \prime}$ & $3^{\prime \prime}$ & $5^{\prime \prime}$ \\
\cline { 2 - 6 } Settling $t=0.25 \mathrm{hr}$ & $0^{\prime \prime}$ & $1^{\prime \prime}$ & $2^{\prime \prime}$ & $3^{\prime \prime}$ & $5^{\prime \prime}$ \\
\cline { 2 - 6 } Settling $t=0.50 \mathrm{hr}$ & $0^{\prime \prime}$ & $1^{\prime \prime}$ & $2^{\prime \prime}$ & $3^{\prime \prime}$ & $5^{\prime \prime}$ \\
\cline { 2 - 6 } Settling $t=1.25 \mathrm{hr}$ & $0^{\prime \prime}$ & $1^{\prime \prime}$ & $2^{\prime \prime}$ & $3^{\prime \prime}$ & $5^{\prime \prime}$ \\
\cline { 2 - 6 } Settling $t=2.25 \mathrm{hr}$ & $0^{\prime \prime}$ & $1^{\prime \prime}$ & $2^{\prime \prime}$ & $3^{\prime \prime}$ & $5^{\prime \prime}$ \\
\cline { 2 - 6 } Settling $t=3.25 \mathrm{hr}$ & $0^{\prime \prime}$ & $1^{\prime \prime}$ & $2^{\prime \prime}$ & $3^{\prime \prime}$ & $5^{\prime \prime}$ \\
\cline { 2 - 6 } Settling $t=4.25 \mathrm{hr}$ & $0^{\prime \prime}$ & $1^{\prime \prime}$ & $2^{\prime \prime}$ & $3^{\prime \prime}$ & $5^{\prime \prime}$ \\
\cline { 2 - 6 } Settling $t=5.25 \mathrm{hr}$ & $0^{\prime \prime}$ & $1^{\prime \prime}$ & $2^{\prime \prime}$ & $3^{\prime \prime}$ & $5^{\prime \prime}$ \\
\cline { 2 - 6 } Settling $t=6.25 \mathrm{hr}$ & $0^{\prime \prime}$ & $1^{\prime \prime}$ & $2^{\prime \prime}$ & $3^{\prime \prime}$ & $5^{\prime \prime}$ \\
\cline { 2 - 6 } Settling $t=7.25 \mathrm{hr}$ & $0^{\prime \prime}$ & $1^{\prime \prime}$ & $2^{\prime \prime}$ & $3^{\prime \prime}$ & $5^{\prime \prime}$ \\
\hline
\end{tabular}

Table .1: The above table shows how many samples were taken during the digestion and settling periods, the time the samples were taken, and the location of the sample with respect to the bottom of the vessel.

\begin{tabular}{|c|c|c|c|c|c|c|c|}
\hline Situation & $\# 1$ & \#2 & $\# 3$ & $\# 4$ & \#5 & \#6 & $\# 7$ \\
\hline \multirow{3}{*}{$\begin{array}{l}\text { Supernate Profile Variac } 50 \% \\
\text { Supernate Profile Variac } 65 \% \\
\text { Supernate Profile Variac } 80 \%\end{array}$} & $\overline{1 " \prime}$ & $2^{\prime \prime}$ & $\overline{3 " 3}$ & 4 4" & $5^{\prime \prime}$ & 6" & $7^{\prime \prime}$ \\
\hline & 1" & $2^{\prime \prime}$ & $3^{\prime \prime}$ & $4^{\prime \prime}$ & $5^{\prime \prime}$ & $6^{\prime \prime}$ & \\
\hline & $0^{\prime \prime \prime}$ & $1^{\prime \prime}$ & $2^{\prime \prime}$ & $3^{\prime \prime}$ & $4^{\prime \prime}$ & $5^{\prime \prime}$ & 6 6" \\
\hline \multirow{10}{*}{$\begin{array}{l}\text { Washing \#1 Solution } \\
\text { Washing \#1 Supernate } \\
\text { Washing \#2 Solution } \\
\text { Washing \#2 Supernate } \\
\text { Washing \#3 Solution } \\
\text { Washing \#3 Supernate } \\
\text { Washing \#4 Solution } \\
\text { Washing \#4 Supernate } \\
\text { Washing \#5 Solution } \\
\text { Washing \#5 Supernate }\end{array}$} & $3^{\prime \prime}$ & 3" & 3" & $3^{\prime \prime}$ & $3^{\prime \prime}$ & & \\
\hline & $3^{\prime \prime}$ & $3^{\prime \prime}$ & $3^{\prime \prime}$ & $3^{\prime \prime}$ & $3^{n}$ & & \\
\hline & $3^{\prime \prime \prime}$ & $3^{3 \prime}$ & $3^{\prime \prime}$ & $3^{\prime \prime}$ & $3^{n}$ & & \\
\hline & 3" & $3^{\prime \prime}$ & $3^{\prime \prime}$ & $3^{\prime \prime}$ & $3^{n}$ & & \\
\hline & 3" & $3^{\prime \prime}$ & $3^{\prime \prime}$ & 3" & $3^{\prime \prime}$ & & \\
\hline & $3^{\prime \prime}$ & $3^{\prime \prime}$ & $3^{\prime \prime}$ & $3^{\prime \prime}$ & $3^{\prime \prime}$ & & \\
\hline & $3^{\prime \prime}$ & $3^{\prime \prime}$ & $3^{\prime \prime}$ & $3^{\prime \prime}$ & $3^{\prime \prime}$ & & \\
\hline & $3^{\prime \prime}$ & 3" & $3^{\prime \prime}$ & 3" & $3^{n}$ & & \\
\hline & $3^{\prime \prime}$ & 3" & $3^{\prime \prime}$ & 3" & $3^{n}$ & & \\
\hline & $3^{\prime \prime}$ & $3^{\prime \prime}$ & $3^{\prime \prime}$ & $3^{\prime \prime}$ & $3^{\prime \prime}$ & & \\
\hline
\end{tabular}

Table .2: This table shows the location and timing of samples to establish the supernate concentration profile. The effect of washing is also measured with samples taken during the washing procedure and the supernate after 24 hours of settling. 


\begin{tabular}{|l|c|c|c|c|c|}
\hline Situation & $\# 1$ & $\# 2$ & $\# 3$ & $\# 4$ & $\# 5$ \\
\hline \hline Simulant & $1, \mathrm{a}$ & $2, \mathrm{a}$ & $3, \mathrm{a}$ & $4, \mathrm{a}$ & $5, \mathrm{a}$ \\
\hline Digestion $t=0.0 \mathrm{hr}$ & $6, \mathrm{a}$ & $7, \mathrm{a}$ & $8, \mathrm{a}$ & $\mathbf{9 , \mathrm { a }}$ & $10, \mathrm{a}$ \\
\cline { 2 - 6 } Digestion $t=1.0 \mathrm{hr}$ & $11, \mathrm{a}$ & $12, \mathrm{a}$ & $13, \mathrm{a}$ & $14, \mathrm{a}$ & $15, \mathrm{a}$ \\
\cline { 2 - 6 } Digestion $t=2.0 \mathrm{hr}$ & $16, \mathrm{a}$ & $17, \mathrm{a}$ & $18, \mathrm{a}$ & $19, \mathrm{a}$ & $20, \mathrm{a}$ \\
\cline { 2 - 6 } Digestion $t=2.5 \mathrm{hr}$ & $26, \mathrm{a}$ & $27, \mathrm{a}$ & $28, \mathrm{a}$ & $29, \mathrm{a}$ & $30, \mathrm{a}$ \\
\cline { 2 - 6 } Digestion $t=3.0 \mathrm{hr}$ & $21, \mathrm{a}$ & $21, \mathrm{a}$ & $23, \mathrm{a}$ & $24, \mathrm{a}$ & $25, \mathrm{a}$ \\
\hline Settling $t=0 \mathrm{hr}$ & $31, \mathrm{~s}$ & $32, \mathrm{~s}$ & $33, \mathrm{a}$ & $34, \mathrm{~s}$ & $35, \mathrm{~s}$ \\
\cline { 2 - 6 } Settling $t=0.25 \mathrm{hr}$ & $36, \mathrm{~s}$ & $37, \mathrm{~s}$ & $38, \mathrm{a}$ & $39, \mathrm{~s}$ & $40, \mathrm{~s}$ \\
\cline { 2 - 6 } Settling $t=0.50 \mathrm{hr}$ & $41, \mathrm{~s}$ & $42, \mathrm{~s}$ & $43, \mathrm{a}$ & $44, \mathrm{~s}$ & $45, \mathrm{~s}$ \\
\cline { 2 - 6 } Settling $t=1.25 \mathrm{hr}$ & $46, \mathrm{~s}$ & $47, \mathrm{~s}$ & $48, \mathrm{a}$ & $49, \mathrm{~s}$ & $50, \mathrm{~s}$ \\
\cline { 2 - 6 } Settling $t=2.25 \mathrm{hr}$ & $51, \mathrm{~s}$ & $52, \mathrm{~s}$ & $53, \mathrm{a}$ & $54, \mathrm{~s}$ & $55, \mathrm{~s}$ \\
\cline { 2 - 6 } Settling $t=3.25 \mathrm{hr}$ & $56, \mathrm{~s}$ & $57, \mathrm{~s}$ & $58, \mathrm{a}$ & $59, \mathrm{~s}$ & $60, \mathrm{~s}$ \\
\cline { 2 - 6 } Settling $t=4.25 \mathrm{hr}$ & $61, \mathrm{~s}$ & $62, \mathrm{~s}$ & $63, \mathrm{a}$ & $64, \mathrm{~s}$ & $65, \mathrm{~s}$ \\
\cline { 2 - 6 } Settling $t=5.25 \mathrm{hr}$ & $66, \mathrm{~s}$ & $67, \mathrm{~s}$ & $68, \mathrm{a}$ & $69, \mathrm{~s}$ & $70, \mathrm{~s}$ \\
\cline { 2 - 6 } Settling $t=6.25 \mathrm{hr}$ & $71, \mathrm{~s}$ & $72, \mathrm{~s}$ & $73, \mathrm{a}$ & $74, \mathrm{~s}$ & $75, \mathrm{~s}$ \\
\cline { 2 - 6 } Settling $t=7.25 \mathrm{hr}$ & $76, \mathrm{~s}$ & $77, \mathrm{~s}$ & $78, \mathrm{a}$ & $79, \mathrm{~s}$ & $80, \mathrm{~s}$ \\
\hline
\end{tabular}

Table .3: The above table shows how the digestion and settling samples samples were submitted for analysis. The letter " $a$ " indicates full analysis, and the letter "s" indicates solids analysis.

\begin{tabular}{|c|c|c|c|c|c|c|c|}
\hline Situation & $\# 1$ & $\# 2$ & $\# 3$ & $\# 4$ & $\# 5$ & $\# 6$ & $\# 7$ \\
\hline \multirow{3}{*}{$\begin{array}{l}\text { Supernate Profile Variac } 50 \% \\
\text { Supernate Profile Variac } 65 \% \\
\text { Supernate Profile Variac } 80 \%\end{array}$} & $81, \mathrm{a}$ & $82, a$ & $83, a$ & $84, \mathrm{a}$ & $85, \mathrm{a}$ & $86, a$ & $87, a$ \\
\hline & $88, a$ & $89, \mathrm{~s}$ & $90, a$ & $91, \mathrm{~s}$ & $92, \mathrm{a}$ & $93, \mathrm{~s}$ & \\
\hline & $94, \mathrm{a}$ & $95, \mathrm{~s}$ & $96, \mathrm{a}$ & $97, \mathrm{~s}$ & $98, a$ & 99,5 & $100, \mathrm{~s}$ \\
\hline \multirow{4}{*}{$\begin{array}{l}\text { Washing \#1 Solution } \\
\text { Washing \#1 Supernate } \\
\text { Washing \#2 Solution } \\
\text { Washing \#2 Supernate }\end{array}$} & $101, \mathrm{~s}$ & $102, \mathrm{~s}$ & $103, \mathrm{~s}$ & $104, \mathrm{~s}$ & $105, \mathrm{~s}$ & & \\
\hline & $106, \mathrm{a}$ & $107, \mathrm{a}$ & $108, a$ & $109, \mathrm{a}$ & $110, \mathrm{a}$ & & \\
\hline & $111, \mathrm{~s}$ & $112, \mathrm{~s}$ & $113, \mathrm{~s}$ & $114, \mathrm{~s}$ & $115, \mathrm{~s}$ & & \\
\hline & $116, a$ & $117, \mathrm{a}$ & $118, \mathrm{a}$ & $119, \mathrm{a}$ & $120, \mathrm{a}$ & & \\
\hline \multirow{2}{*}{$\begin{array}{l}\text { Washing \#3 Solution } \\
\text { Washing \#3 Supernate }\end{array}$} & $121, \mathrm{~s}$ & & & & & & \\
\hline & $122, \mathrm{a}$ & & & & & & \\
\hline \multirow{2}{*}{$\begin{array}{l}\text { Washing \#4 Solution } \\
\text { Washing \#4 Supernate }\end{array}$} & $123, \mathrm{~s}$ & & & & & & \\
\hline & $124, \mathrm{a}$ & & & & & & \\
\hline \multirow{2}{*}{$\begin{array}{l}\text { Washing \#5 Solution } \\
\text { Washing \#5 Supernate }\end{array}$} & $125, \mathrm{~s}$ & & & & & & \\
\hline & $126, \mathrm{a}$ & & & & & & \\
\hline Washing \#5B Supernate & $127, \mathrm{a}$ & & & & & & \\
\hline
\end{tabular}

Table .4: This table shows the analysis required for the concentration profile and the washing procedure. The letter " $a$ " indicates full analysis, and the letter "s" indicates solids analysis. 


\begin{tabular}{|l|c|c|}
\hline Time & Temperature & Observations \\
\hline \hline 5:30am & $53^{\circ} \mathrm{C}$ & noticed stirrer having hard time \\
6:00am & $50^{\circ} \mathrm{C}$ & \\
6:30am & $48^{\circ} \mathrm{C}$ & start digestion, pulled 5 samples \\
\hline 7:00am & $46^{\circ} \mathrm{C}$ & pulled 5 samples \\
\hline 7:30am & $45^{\circ} \mathrm{C}$ & \\
\hline 8:00am & $44^{\circ} \mathrm{C}$ & initial volume $=14$ inches \\
\hline 8:30am & $44^{\circ} \mathrm{C}$ & stirrer starts to bog down, pulled 5 samples \\
\hline 9:00am & $45^{\circ} \mathrm{C}$ & pulled 5 samples \\
\hline 9:30am & $46^{\circ} \mathrm{C}$ & \\
\hline 10:00am & $46^{\circ} \mathrm{C}$ & pulled 5 samples, shut off stirrer \\
\hline 13:30am & $46^{\circ} \mathrm{C}$ & \\
\hline
\end{tabular}

Table .5: Observations at the start of digestion.

\begin{tabular}{|c|c|c|}
\hline Time & Temperature & Observations \\
\hline \hline 0 & $47^{\circ} \mathrm{C}$ & Pulled 6", $7^{\prime \prime}, 8^{\prime \prime}, 9^{\prime \prime}, 11^{\prime \prime}$ Solution appeared murky \\
15 & $47^{\circ} \mathrm{C}$ & Pulled 6", $7^{\prime \prime}, 8^{\prime \prime}, 9^{\prime \prime}, 11^{\prime \prime}$ \\
30 & $47^{\circ} \mathrm{C}$ & Pulled 6", $7^{\prime \prime}, 8^{\prime \prime}, 9^{\prime \prime}, 11^{\prime \prime}$ \\
\hline $1: 15$ & $47^{\circ} \mathrm{C}$ & Pulled 6", $7^{\prime \prime}, 8^{\prime \prime}, 9^{\prime \prime}, 11^{\prime \prime}$ Top two rungs of coil visible \\
\hline $2: 15$ & $46^{\circ} \mathrm{C}$ & Pulled 6", $7^{\prime \prime}, 8^{\prime \prime}, 9^{\prime \prime}, 11^{\prime \prime}$ Precipitate noticed on heating coils \\
\hline $3: 15$ & $45^{\circ} \mathrm{C}$ & Pulled 6", $7^{\prime \prime}, 8^{\prime \prime}, 9^{\prime \prime}, 11^{\prime \prime}$ \\
\hline $4: 15$ & $46^{\circ} \mathrm{C}$ & Pulled 6", $7^{\prime \prime}, 8^{\prime \prime}, 9^{\prime \prime}, 11^{\prime \prime}$ \\
\hline $5: 15$ & $46^{\circ} \mathrm{C}$ & Pulled 6", $7^{\prime \prime}, 8^{\prime \prime}, 9^{\prime \prime}, 11^{\prime \prime}$ \\
\hline $6: 15$ & $46^{\circ} \mathrm{C}$ & Pulled 6", $7^{\prime \prime}, 8^{\prime \prime}, 9^{\prime \prime}, 11^{\prime \prime}$ \\
\hline $7: 15$ & $46^{\circ} \mathrm{C}$ & Pulled 6", $7^{\prime \prime}, 8^{\prime \prime}, 9^{\prime \prime}, 11^{\prime \prime}$ \\
\hline
\end{tabular}

Table .6: Sampling protocol during the settling stage. 
